\title{
Fuzzy inverse logic: part-2. validation and evaluation of the method
}

\author{
Bulanık ters mantık: kısım-2. yöntemin doğrulanması ve değerlendirilmesi
}

Ertekin ÖZTEKIN*1,a

${ }^{I}$ Gümüşhane University, Faculty of Engineering and Natural Sciences, Civil Engineering Department,29100, Gümüşhane

\begin{tabular}{|c|c|c|}
\hline - Geliş tarihi / Received: 11.03 .2021 & - Düzeltilerek geliş tarihi / Received in revised form: 23.04 .2021 & - Kabul tarihi / Accepted: 08.05.2021 \\
\hline
\end{tabular}

\begin{abstract}
In the first part of this study, which consists of two parts, the introduction of the fuzzy inverse logic method, its foundations, computation and process flow and details were given. In this second part, the method was applied on a very simple mathematical problem and on a simple civil engineering design problem in order to investigate and evaluate the validity of the method easily. Fuzzy inverse logic computations have been carried out on these two simple problems for different dimension, sensitivity and acceptable error values. By comparing the obtained results with the desired outputs and mathematical results, the effective computation ability of the method was tried to be revealed. As a result, it is understood that the method developed in this study has many promising aspects in terms of theoretical computations and practical applications and can be used effectively in many scientific fields.
\end{abstract}

Keywords: Artificial intelligence, Design, Engineering, Fuzzy logic, Fuzzy inverse logic, Logic.

$\ddot{o} z$

Bulanık ters mantık yönteminin anlatıldı̆̆ ve iki kısımdan oluşan çalışmanın birinci kısmında yöntemin tanıtımı, dayandiğı temeller, hesap ve işlem akış ve detaylarının verilmişstir. Bu ikinci kısımda ise yöntemin geçerliliğinin kolayca araştırllarak değerlendirilebilmesi için yöntem çok basit bir matematik problem ile inşaat mühendisliğinde basit bir tasarım problemi üzerine uygulanmıştır. Bu basit problemler üzerinde farkl boyut, hassasiyet ve kabul edilebilir hata değerleri için Bulanık ters mantık çözümlemeleri gerçekleştirilmiştir. Elde edilen sonuçlar ile hedeflenen ve matematiksel sonuçlar karşılaş̧tırlarak yöntemin etkin hesap yapabilme yeteneği ortaya konulmaya çalışılmıştır. Çalışmadan elde edilen bulgular detaylıca değerlendirilerek yöntemin avantajları, dezavantajları belirlenmeye çalışılmıştır. Sonuç olarak bu çalışmada geliş̧tirilen yöntemin teorik hesaplamalar ve pratik uygulamalar açısından ümit verici birçok yönü olduğu ve birçok alanda etkili olarak kullanılabileceği anlaşılmıştır.

Anahtar kelimeler: Yapay zekâ, Tasarım, Mühendislik, Bulanık mantık, Bulanık ters mantık, Mantık

\footnotetext{
${ }^{{ }^{*} a}$ Ertekin ÖZTEKIN; ertekinoztekin@ @otmail.com, Tel: (0532) 777 26 67, orcid.org/0000-0002-4229-0953
} 


\section{Introduction}

Human beings solve the problems they encounter in their daily life by making various inferences based on theirs past experiences. These inferences are in two directions. In other words, a person can make inferences from cause to result as well as from result to cause. Fuzzy logic method has been developed by considering the inferences made from cause to result. For the inferences that humans can make from result to cause, the FIL method developed in this study is tried to be explained.

In the first part of this study, where the fuzzy inverse logic method was presented, the fundamentals, computation and process flow of the method were tried to be explained in detail. In this second part of the study, the effectiveness and validity of the method was tried to be determined and evaluated in the light of the results obtained by applying the FIL method on two very simple problems. The first of the two problems in which the FIL method applied is on a very simple mathematical problem. In order to make more clear and understandable evaluations and to provide better explanations about the method, a very simple problem was chosen in this study firstly. The second problem, which is more complex than the first problem, was chosen from the field of civil engineering. Although the second example seems complex compared to the first example, it is one of the simplest design examples in the field of civil engineering.

In this study, a general purpose computer code was written in order to apply the developed fuzzy inverse logic method on the two examples described above. For this, vb.net visual basic programming language is used. By means of this computer code whose flow chart is given in Figure 1, the FIL method has been successfully applied on the above-mentioned examples and by this way a possibility was provided to test the method and to make evaluations on this method. As seen Figure 1 that, the flow chart of the written code is constituted from two parts. First part includes the classic fuzzy model computations. The second part was added to the first part to apply FIL method on a developed fuzzy model.

\section{Applications of the FIL method on problems}

\subsection{Application of the FIL method on problem-1 (on a simple mathematic problem)}

Let, $A, B$ and $C \in R$ and $1 \leq A \leq 5,1 \leq B \leq 5$ and $1 \leq$ $C \leq 5$, a) If $A+B+C=4.5$ then find $A, B$ and $C$.

b) If $(A+B) x C=10.5$ then find $A, B$ and $C$.

\subsubsection{Mathematical solution}

Since the parameters A, B and C are real numbers between 1 and 5 , it should be emphasized here that mathematically there are infinite number of solutions for this problem. The mathematical solution of both a and $b$ options of this problem can be achieved by assigning values between 1 and 5 to the parameters of $\mathrm{A}, \mathrm{B}$ and $\mathrm{C}$ by trial and error method. Since the solutions are very simple mathematically, they will not be explained here.

\subsubsection{Solution by FIL}

\subsubsection{Constitution of FL model for problem-1}

As it is known, in order to obtain accurate and precise solutions with the FIL method, it should be applied on a FL model having proven accuracy and sensitivity. Since the variable parameters are the same for the a and b options, it was preferred to constitute single fuzzy model instead of creating separate fuzzy models for both of these options.

The first step in the constitution of a FL model is determination of fuzzy sets for input and output parameters. For each of the A, B and C parameters the fuzzy sets shown in Figure 2 (a), Figure 2 (b) and Figure 2 (c) are defined respectively. As can be seen from these figures, triangular membership functions are used in the constitution of fuzzy sets. In the fuzzy model, 13 fuzzy sets for the first output $O_{1}=A+B+C$ and 27 fuzzy sets for the second output $\mathrm{O}_{2}=(A+B) x C$ were constituted as in Figure 3 and Figure 4.

The Weighted Average Method (WAM) was used in the de-fuzzification in FL in which 125 rules were constituted with combinations of fuzzy sets of input parameters for both outputs. The model was tested for 50 different samples given in Table 1 for each output. In the test results, the correlation and the correlation coefficients for both $\mathrm{O}_{1}$ and $\mathrm{O}_{2}$ output were obtained as $\mathrm{R}=0.996$ and as $\mathrm{R}^{2}=$ 0.992 respectively. For each of the $\mathrm{O}_{1}$ and $\mathrm{O}_{2}$ outputs, the average absolute \% error was calculated as 1.543 and 3.853, while the maximum absolute \% error was calculated as 4.986 and 11.061. The absolute \% error (APE) formula given in Equation-1 was used in this study.

$$
A P E=\frac{\left|O_{\text {predicted }-} O_{\text {real }}\right|}{O_{\text {real }}} \times 100
$$




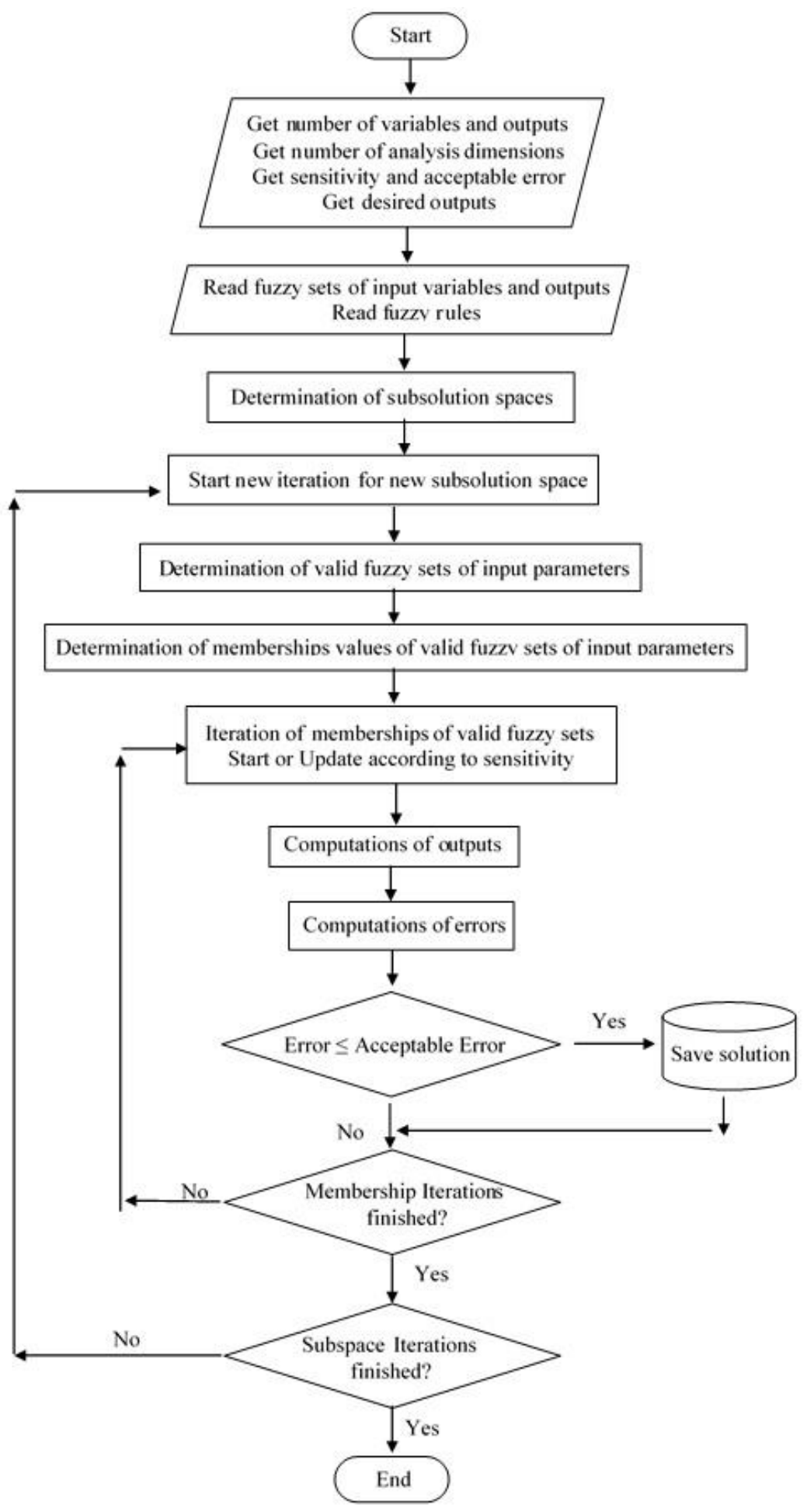

Figure 1. Computation steps of the fuzzy inverse logic algorithms
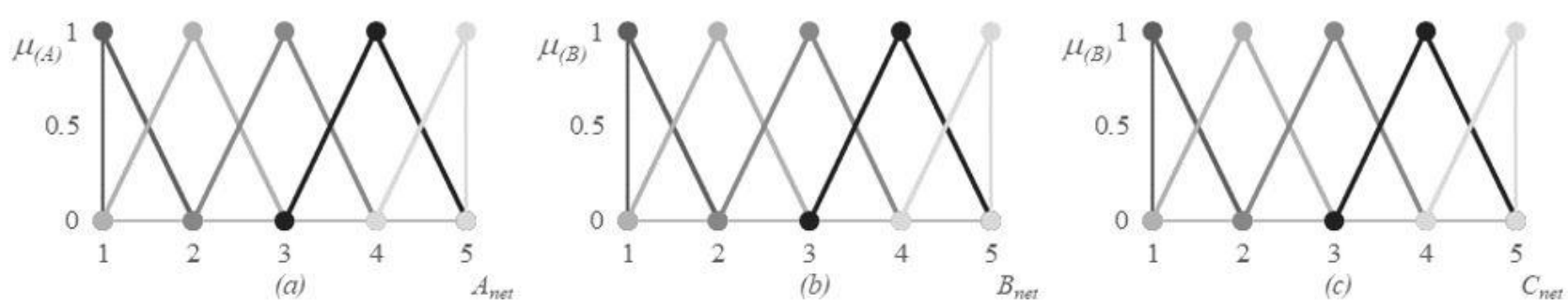

Figure 2. Fuzzy sets for A, B and C parameters 


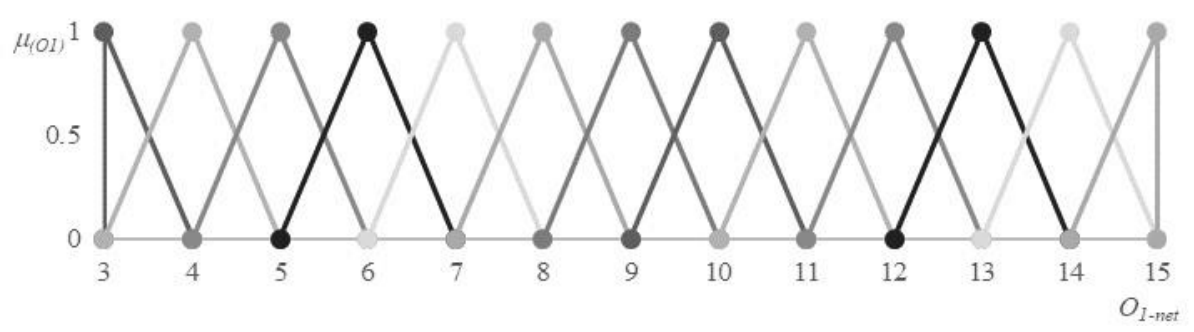

Figure 3. Fuzzy sets for the output parameter of $O_{1}$

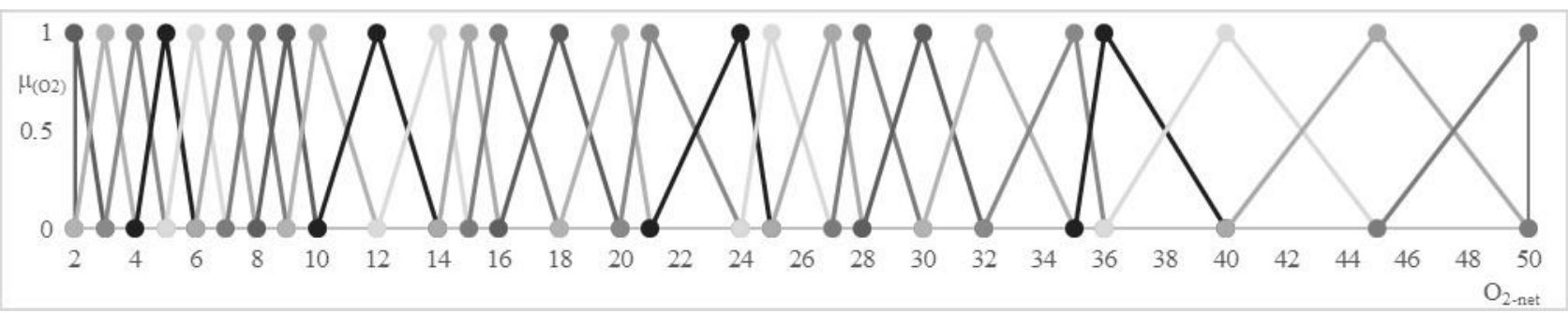

Figure 4. Fuzzy sets for the output parameter of $\mathrm{O}_{2}$

Table 1. Test data and FL outputs

\begin{tabular}{cccccccc}
\hline & \multicolumn{3}{c}{ Test Data } & \multicolumn{3}{c}{ Mathematical } \\
Outputs & FL Outputs \\
\hline No & $A$ & $B$ & $C$ & $O_{1}$ & $O_{2}$ & $O_{1}$ & $O_{2}$ \\
\hline 1 & 4.9 & 4.1 & 3.9 & 12.9 & 35.1 & 12.750 & 34.347 \\
2 & 4.8 & 4.6 & 2.4 & 11.8 & 22.56 & 11.692 & 22.474 \\
3 & 4.75 & 2.75 & 2.4 & 9.9 & 18 & 9.660 & 17.727 \\
4 & 3.4 & 4.35 & 3.4 & 11.15 & 26.35 & 11.375 & 27.638 \\
5 & 3.7 & 1.95 & 1.75 & 7.4 & 9.8875 & 7.147 & 9.208 \\
6 & 3.55 & 1.8 & 2 & 7.35 & 10.7 & 7.250 & 10.693 \\
7 & 1.65 & 2.45 & 1 & 5.1 & 4.1 & 5.059 & 4.059 \\
8 & 4.25 & 2.25 & 2.4 & 8.9 & 15.6 & 9.260 & 16.804 \\
9 & 4.4 & 1.4 & 2.65 & 8.45 & 15.37 & 8.500 & 15.290 \\
10 & 2.8 & 2 & 1 & 5.8 & 4.8 & 5.800 & 4.800 \\
11 & 3.3 & 3.65 & 3.9 & 10.85 & 27.105 & 10.775 & 26.648 \\
12 & 3.3 & 2.85 & 1.45 & 7.6 & 8.9175 & 7.614 & 9.041 \\
13 & 3.55 & 3.6 & 1.65 & 8.8 & 11.7975 & 8.609 & 10.989 \\
14 & 4.6 & 1.4 & 2.3 & 8.3 & 13.8 & 8.400 & 14.486 \\
15 & 2.15 & 3.8 & 4.85 & 10.8 & 28.8575 & 10.658 & 27.802 \\
16 & 3.35 & 3.45 & 2.55 & 9.35 & 17.34 & 9.424 & 17.418 \\
17 & 1.7 & 1.35 & 3.8 & 6.85 & 11.59 & 6.688 & 11.144 \\
18 & 1.55 & 3.1 & 3.35 & 8 & 15.5775 & 8.143 & 16.099 \\
19 & 4.45 & 4.45 & 2.7 & 11.6 & 24.03 & 11.581 & 23.169 \\
20 & 4 & 4.7 & 3.6 & 12.3 & 31.32 & 12.188 & 30.985 \\
21 & 3.1 & 1.5 & 2.05 & 6.65 & 9.43 & 6.857 & 10.316 \\
22 & 3.45 & 1.85 & 1.45 & 6.75 & 7.685 & 6.720 & 7.860 \\
23 & 2.75 & 1.45 & 3.95 & 8.15 & 16.59 & 8.000 & 16.082 \\
24 & 1.45 & 4.7 & 1.2 & 7.35 & 7.38 & 7.396 & 8.063 \\
25 & 3.95 & 1.8 & 3.05 & 8.8 & 17.5375 & 8.731 & 17.444 \\
\hline & & & & & & &
\end{tabular}

\begin{tabular}{cccccccc}
\hline & \multicolumn{1}{c}{ Test Data } & \multicolumn{5}{c}{$\begin{array}{c}\text { MathematicalO } \\
\text { utputs }\end{array}$} & FL Outputs \\
\hline No & $A$ & $B$ & $C$ & $O_{1}$ & $O_{2}$ & $O_{1}$ & $O_{2}$ \\
\hline 26 & 2.4 & 4.8 & 4.8 & 13.05 & 39.6 & 12.750 & 37.959 \\
27 & 3.15 & 2.5 & 2.7 & 9.4 & 18.09 & 9.417 & 17.733 \\
28 & 3.45 & 4.5 & 4.3 & 9.8 & 23.65 & 9.875 & 23.778 \\
29 & 4.2 & 3.6 & 4.05 & 9.85 & 23.49 & 10.000 & 23.798 \\
30 & 1 & 3.55 & 2.1 & 6.9 & 10.08 & 7.105 & 11.010 \\
31 & 2.2 & 1.05 & 2.05 & 7.35 & 10.865 & 7.615 & 12.067 \\
32 & 1.25 & 4.15 & 2.85 & 8.95 & 17.385 & 8.867 & 16.796 \\
33 & 4.25 & 2.9 & 2.15 & 6.6 & 9.5675 & 6.588 & 9.917 \\
34 & 1.95 & 4.15 & 2.55 & 8.55 & 15.3 & 8.526 & 15.231 \\
35 & 1.55 & 4.35 & 2.65 & 8.95 & 16.695 & 8.895 & 16.353 \\
36 & 1.85 & 1.35 & 1.35 & 5.4 & 5.4675 & 5.483 & 5.895 \\
37 & 1.95 & 1.35 & 1.85 & 5.25 & 6.29 & 5.267 & 6.083 \\
38 & 2.7 & 3.6 & 1.7 & 9.2 & 12.75 & 8.950 & 11.806 \\
39 & 2.05 & 3.2 & 4.15 & 9.5 & 22.2025 & 9.974 & 24.213 \\
40 & 3.9 & 2.9 & 4.05 & 9.55 & 22.275 & 9.500 & 21.725 \\
41 & 2.15 & 4.6 & 1.7 & 10.85 & 15.555 & 10.650 & 14.528 \\
42 & 2.6 & 3.25 & 1.7 & 9.2 & 12.75 & 9.380 & 12.248 \\
43 & 4.55 & 4.45 & 4.75 & 11.6 & 32.5375 & 11.589 & 32.085 \\
44 & 4.25 & 1.75 & 3.65 & 7.45 & 13.87 & 7.353 & 13.668 \\
45 & 2.4 & 2 & 2.75 & 8.6 & 16.0875 & 8.462 & 15.630 \\
46 & 2.05 & 4.8 & 4.35 & 12.55 & 35.67 & 12.580 & 36.520 \\
47 & 3.85 & 3.7 & 1.6 & 8.9 & 11.68 & 8.667 & 10.944 \\
48 & 3.4 & 2.3 & 2.35 & 7.5 & 12.1025 & 7.568 & 12.639 \\
49 & 3.6 & 2.3 & 4.3 & 9 & 20.21 & 9.321 & 21.644 \\
50 & 2.85 & 2.25 & 4.2 & 9.6 & 22.68 & 10.025 & 24.475 \\
\hline & & & & & & &
\end{tabular}

\subsubsection{Application of FIL method on FL model} constituted for problem 1

a) By entering of the value of $\mathrm{O}_{1}=4.5$ as desired output into the program coded for the FIL method, the values of $\mathrm{A}, \mathrm{B}$ and $\mathrm{C}$ parameters were computed in 1 dimensional (1D), 2 dimensional (2D) and 3 dimensional (3D) analyzes and were given in Table 2, Table 3 and Table 4, respectively. As can be seen from these three tables, 9, 24 and 36 solutions were obtained in $1 \mathrm{D}, 2 \mathrm{D}$ and $3 \mathrm{D}$ FIL analyzes for $\mathrm{O}_{1}=\mathrm{A}+\mathrm{B}+\mathrm{C}=4.5$, respectively.

b) By entering of the value of $\mathrm{O}_{2}=10.5$ as desired output into the program coded for the FIL method, the values of $\mathrm{A}, \mathrm{B}$ and $\mathrm{C}$ parameters were computed in 1D, 2D and 3D analyzes and were given in Table 5, Table 6 and Table 7, respectively. As can be seen from these three tables, 16, 57 and 132 solutions were obtained in 1D, 2D and 3D FIL analyzes for $\mathrm{O}_{2}=(A+B \times C=10.5$, respectively.

These solutions are not completely different solutions. In other words, for reasons arising from the nature of iteration computations, some 
solutions, even if they are small amount, were obtained identical to each other. This is an indication that the program developed for FIL produces correct results. The solutions given in
Table 2, Table 3 and Table 4, Table 5, Table 6 and Table 7 were obtained for $\% 0$ absolute $\%$ error (APE) of FIL and for 0.1 membership sensitivity in this study.

Table 2. 1D solution for $O_{1}$

\begin{tabular}{ccccccccc}
\hline $\begin{array}{c}\text { Solution } \\
\text { No }\end{array}$ & $A$ & $B$ & $C$ & $\begin{array}{c}\text { Mathematical } \\
\text { Solution } \\
(M S=A+B+C)\end{array}$ & $\begin{array}{c}F I L \\
\text { Solution } \\
(F I L S)\end{array}$ & $\begin{array}{c}\text { Desired } \\
\text { Value } \\
(D V)\end{array}$ & $\begin{array}{c}\text { Internal APE } \\
\frac{|F I L S-D V|}{D V} \times 100\end{array}$ & $\begin{array}{c}\text { External APE } \\
\end{array}$ \\
\hline 1 & 2.5 & 1 & 1 & 4.5 & 4.5 & 4.5 & 0 & \\
2 & 1.5 & 2 & 1 & 4.5 & 4.5 & 4.5 & 0 & 0 \\
3 & 1.5 & 1 & 2 & 4.5 & 4.5 & 4.5 & 0 & 0 \\
4 & 2 & 1.5 & 1 & 4.5 & 4.5 & 4.5 & 0 & 0 \\
5 & 1 & 2.5 & 1 & 4.5 & 4.5 & 4.5 & 0 & 0 \\
6 & 1 & 1.5 & 2 & 4.5 & 4.5 & 4.5 & 0 & 0 \\
7 & 2 & 1 & 1.5 & 4.5 & 4.5 & 4.5 & 0 & 0 \\
8 & 1 & 2 & 1.5 & 4.5 & 4.5 & 4.5 & 0 & 0 \\
9 & 1 & 1 & 2.5 & 4.5 & 4.5 & 4.5 & 0 & 0 \\
\hline
\end{tabular}

Table 3. 2D solution for $O_{1}$

\begin{tabular}{ccccccccc}
\hline $\begin{array}{c}\text { Solution } \\
\text { No }\end{array}$ & $A$ & $B$ & $C$ & $\begin{array}{c}\text { Mathematical } \\
\text { Solution } \\
(M S=A+B+C)\end{array}$ & $\begin{array}{c}\text { FIL } \\
\text { Solution } \\
(\text { FILS })\end{array}$ & $\begin{array}{c}\text { Desired } \\
\text { Value } \\
(D V)\end{array}$ & $\frac{\mid \text { FILS }-D V \mid}{D V} \times 100$ & $\frac{|M S-D V|}{D V} \times 100$ \\
\hline 1 & & & & & & & & \\
2 & 2 & 1.5 & 1 & 4.5 & 4.5 & 4.5 & 0 & 0 \\
3 & 2 & 1.5 & 1 & 4.5 & 4.5 & 4.5 & 0 & 0 \\
4 & 2.5 & 1 & 1 & 4.5 & 4.5 & 4.5 & 0 & 0 \\
5 & 1 & 2.5 & 1 & 4.5 & 4.5 & 4.5 & 0 & 0 \\
6 & 1.5 & 2 & 1 & 4.5 & 4.5 & 4.5 & 0 & 0 \\
7 & 1 & 1.5 & 2 & 4.5 & 4.5 & 4.5 & 0 & 0 \\
8 & 1.5 & 1 & 2 & 4.5 & 4.5 & 4.5 & 0 & 0 \\
9 & 1.5 & 1 & 2 & 4.5 & 4.5 & 4.5 & 0 & 0 \\
10 & 2 & 1 & 1.5 & 4.5 & 4.5 & 4.5 & 0 & 0 \\
11 & 2 & 1 & 1.5 & 4.5 & 4.5 & 4.5 & 0 & 0 \\
12 & 2.5 & 1 & 1 & 4.5 & 4.5 & 4.5 & 0 & 0 \\
13 & 1 & 2 & 1.5 & 4.5 & 4.5 & 4.5 & 0 & 0 \\
14 & 1.5 & 2 & 1 & 4.5 & 4.5 & 4.5 & 0 & 0 \\
15 & 1 & 1 & 2.5 & 4.5 & 4.5 & 4.5 & 0 & 0 \\
16 & 1.5 & 1 & 2 & 4.5 & 4.5 & 4.5 & 0 & 0 \\
17 & 1 & 1.5 & 2 & 4.5 & 4.5 & 4.5 & 0 & 0 \\
18 & 1 & 2 & 1.5 & 4.5 & 4.5 & 4.5 & 0 & 0 \\
19 & 2 & 1 & 1.5 & 4.5 & 4.5 & 4.5 & 0 & 0 \\
20 & 2 & 1.5 & 1 & 4.5 & 4.5 & 4.5 & 0 & 0 \\
21 & 1 & 2 & 1.5 & 4.5 & 4.5 & 4.5 & 0 & 0 \\
22 & 1 & 2.5 & 1 & 4.5 & 4.5 & 4.5 & 0 & 0 \\
23 & 1 & 1 & 2.5 & 4.5 & 4.5 & 4.5 & 0 & 0 \\
24 & 1 & 1.5 & 2 & 4.5 & 4.5 & 4.5 & 0 & 0 \\
\hline & & & & & & Average APE & 0 & 0 \\
\hline
\end{tabular}


Table 4. 3D solution for $O_{I}$

\begin{tabular}{|c|c|c|c|c|c|c|c|c|}
\hline $\begin{array}{l}\text { Solution } \\
\quad \text { No }\end{array}$ & $A$ & $B$ & $C$ & $\begin{array}{l}\text { Mathematical } \\
\text { Solution } \\
(M S=A+B+C)\end{array}$ & $\begin{array}{c}\text { FIL } \\
\text { Solution } \\
(\text { FILS })\end{array}$ & $\begin{array}{l}\text { Desired } \\
\text { Value } \\
(D V)\end{array}$ & $\begin{array}{c}\text { Internal APE } \\
\frac{|F I L S-D V|}{D V} \times 100\end{array}$ & $\begin{array}{c}\text { External APE } \\
\frac{|M S-D V|}{D V} \times 100\end{array}$ \\
\hline 1 & 1 & 1.5 & 2 & 4.5 & 4.5 & 4.5 & 0 & 0 \\
\hline 2 & 1.5 & 1 & 2 & 4.5 & 4.5 & 4.5 & 0 & 0 \\
\hline 3 & 1.2 & 1.3 & 1.9 & 4.4 & 4.5 & 4.5 & 0 & 2.22 \\
\hline 4 & 1.3 & 1.2 & 1.9 & 4.4 & 4.5 & 4.5 & 0 & 2.22 \\
\hline 5 & 1.1 & 1.7 & 1.8 & 4.6 & 4.5 & 4.5 & 0 & 2.22 \\
\hline 6 & 1.3 & 1.3 & 1.8 & 4.4 & 4.5 & 4.5 & 0 & 2.22 \\
\hline 7 & 1.1 & 1.8 & 1.7 & 4.6 & 4.5 & 4.5 & 0 & 2.22 \\
\hline 8 & 1.4 & 1.5 & 1.6 & 4.5 & 4.5 & 4.5 & 0 & 0 \\
\hline 9 & 1.5 & 1.4 & 1.6 & 4.5 & 4.5 & 4.5 & 0 & 0 \\
\hline 10 & 1 & 2 & 1.5 & 4.5 & 4.5 & 4.5 & 0 & 0 \\
\hline 11 & 1.2 & 1.8 & 1.5 & 4.5 & 4.5 & 4.5 & 0 & 0 \\
\hline 12 & 1.4 & 1.6 & 1.5 & 4.5 & 4.5 & 4.5 & 0 & 0 \\
\hline 13 & 1.5 & 1.5 & 1.5 & 4.5 & 4.5 & 4.5 & 0 & 0 \\
\hline 14 & 1.6 & 1.4 & 1.5 & 4.5 & 4.5 & 4.5 & 0 & 0 \\
\hline 15 & 1.8 & 1.2 & 1.5 & 4.5 & 4.5 & 4.5 & 0 & 0 \\
\hline 16 & 2 & 1 & 1.5 & 4.5 & 4.5 & 4.5 & 0 & 0 \\
\hline 17 & 1.5 & 1.6 & 1.4 & 4.5 & 4.5 & 4.5 & 0 & 0 \\
\hline 18 & 1.6 & 1.5 & 1.4 & 4.5 & 4.5 & 4.5 & 0 & 0 \\
\hline 19 & 1.2 & 1.9 & 1.3 & 4.4 & 4.5 & 4.5 & 0 & 2.22 \\
\hline 20 & 1.3 & 1.8 & 1.3 & 4.4 & 4.5 & 4.5 & 0 & 2.22 \\
\hline 21 & 1.8 & 1.3 & 1.3 & 4.4 & 4.5 & 4.5 & 0 & 2.22 \\
\hline 22 & 1.9 & 1.2 & 1.3 & 4.4 & 4.5 & 4.5 & 0 & 2.22 \\
\hline 23 & 1.3 & 1.9 & 1.2 & 4.4 & 4.5 & 4.5 & 0 & 2.22 \\
\hline 24 & 1.8 & 1.5 & 1.2 & 4.5 & 4.5 & 4.5 & 0 & 0 \\
\hline 25 & 1.9 & 1.3 & 1.2 & 4.4 & 4.5 & 4.5 & 0 & 2.22 \\
\hline 26 & 1.5 & 2 & 1 & 4.5 & 4.5 & 4.5 & 0 & 0 \\
\hline 27 & 2 & 1.5 & 1 & 4.5 & 4.5 & 4.5 & 0 & 0 \\
\hline 28 & 2 & 1 & 1.5 & 4.5 & 4.5 & 4.5 & 0 & 0 \\
\hline 29 & 2 & 1.5 & 1 & 4.5 & 4.5 & 4.5 & 0 & 0 \\
\hline 30 & 2.5 & 1 & 1 & 4.5 & 4.5 & 4.5 & 0 & 0 \\
\hline 31 & 1 & 2 & 1.5 & 4.5 & 4.5 & 4.5 & 0 & 0 \\
\hline 32 & 1 & 2.5 & 1 & 4.5 & 4.5 & 4.5 & 0 & 0 \\
\hline 33 & 1.5 & 2 & 1 & 4.5 & 4.5 & 4.5 & 0 & 0 \\
\hline 34 & 1 & 1 & 2.5 & 4.5 & 4.5 & 4.5 & 0 & 0 \\
\hline 35 & 1 & 1.5 & 2 & 4.5 & 4.5 & 4.5 & 0 & 0 \\
\hline \multirow[t]{3}{*}{36} & 1.5 & 1 & 2 & 4.5 & 4.5 & 4.5 & 0 & 0 \\
\hline & & & & & & erage APE & 0 & 0.68 \\
\hline & & & & & & Max APE & 0 & 2.22 \\
\hline
\end{tabular}

Table 5. 1D solution for $\mathrm{O}_{2}$

\begin{tabular}{|c|c|c|c|c|c|c|c|c|}
\hline $\begin{array}{c}\text { Solution } \\
\quad \text { No }\end{array}$ & $A$ & $B$ & $C$ & $\begin{array}{l}\text { Mathematical } \\
\text { Solution } \\
(M S=(A+B) x C)\end{array}$ & $\begin{array}{c}\text { FIL } \\
\text { Solution } \\
(\text { FILS) }\end{array}$ & $\begin{array}{l}\text { Desired } \\
\text { Value } \\
(D V)\end{array}$ & $\begin{array}{c}\text { Internal APE } \\
\frac{|F I L S-D V|}{D V} \times 100\end{array}$ & $\begin{array}{c}\text { External APE } \\
\frac{|M S-D V|}{D V} \times 100\end{array}$ \\
\hline 1 & 2.5 & 1 & 3 & 10.5 & 10.5 & 10.5 & 0 & 0 \\
\hline 2 & 1.5 & 2 & 3 & 10.5 & 10.5 & 10.5 & 0 & 0 \\
\hline 3 & 1.1 & 1 & 5 & 10.5 & 10.5 & 10.5 & 0 & 0 \\
\hline 4 & 2 & 1.5 & 3 & 10.5 & 10.5 & 10.5 & 0 & 0 \\
\hline 5 & 1 & 2.5 & 3 & 10.5 & 10.5 & 10.5 & 0 & 0 \\
\hline 6 & 1 & 1.1 & 5 & 10.5 & 10.5 & 10.5 & 0 & 0 \\
\hline 7 & 5 & 2 & 1.5 & 10.5 & 10.5 & 10.5 & 0 & 0 \\
\hline 8 & 4 & 3 & 1.5 & 10.5 & 10.5 & 10.5 & 0 & 0 \\
\hline 9 & 3 & 4 & 1.5 & 10.5 & 10.5 & 10.5 & 0 & 0 \\
\hline 10 & 2 & 5 & 1.5 & 10.5 & 10.5 & 10.5 & 0 & 0 \\
\hline 11 & 4 & 1 & 2.1 & 10.5 & 10.5 & 10.5 & 0 & 0 \\
\hline 12 & 3 & 2 & 2.1 & 10.5 & 10.5 & 10.5 & 0 & 0 \\
\hline 13 & 2 & 3 & 2.1 & 10.5 & 10.5 & 10.5 & 0 & 0 \\
\hline 14 & 1 & 4 & 2.1 & 10.5 & 10.5 & 10.5 & 0 & 0 \\
\hline 15 & 2 & 1 & 3.5 & 10.5 & 10.5 & 10.5 & 0 & 0 \\
\hline \multirow[t]{3}{*}{16} & 1 & 2 & 3.5 & 10.5 & 10.5 & 10.5 & 0 & 0 \\
\hline & & & & & & verage APE & 0 & 0 \\
\hline & & & & & & Max APE & 0 & 0 \\
\hline
\end{tabular}


Table 6. 2D solution for $\mathrm{O}_{2}$

\begin{tabular}{|c|c|c|c|c|c|c|c|c|}
\hline $\begin{array}{l}\text { Solution } \\
\text { No }\end{array}$ & $A$ & $B$ & $C$ & $\begin{array}{c}\text { Mathematical } \\
\text { Solution } \\
(M S=(A+B) x C)\end{array}$ & $\begin{array}{c}\text { FIL } \\
\text { Solution } \\
\text { (FILS) }\end{array}$ & $\begin{array}{l}\text { Desired } \\
\text { Value } \\
(D V)\end{array}$ & $\begin{array}{c}\text { Internal APE } \\
\frac{|F I L S-D V|}{D V} \times 100\end{array}$ & $\begin{array}{c}\text { External APE } \\
\frac{|M S-D V|}{D V} \times 100\end{array}$ \\
\hline 1 & 3.4 & 1.9 & 2 & 10.6 & 10.5 & 10.5 & 0 & 0.952 \\
\hline 2 & 2.4 & 2.9 & 2 & 10.6 & 10.5 & 10.5 & 0 & 0.952 \\
\hline 3 & 1.4 & 3.9 & 2 & 10.6 & 10.5 & 10.5 & 0 & 0.952 \\
\hline 4 & 1.5 & 2 & 3 & 10.5 & 10.5 & 10.5 & 0 & 0 \\
\hline 5 & 2 & 1.5 & 3 & 10.5 & 10.5 & 10.5 & 0 & 0 \\
\hline 6 & 2 & 1.5 & 3 & 10.5 & 10.5 & 10.5 & 0 & 0 \\
\hline 7 & 2.1 & 1.3 & 3 & 10.2 & 10.5 & 10.5 & 0 & 2.857 \\
\hline 8 & 2.5 & 1 & 3 & 10.5 & 10.5 & 10.5 & 0 & 0 \\
\hline 9 & 1 & 2.5 & 3 & 10.5 & 10.5 & 10.5 & 0 & 0 \\
\hline 10 & 1.1 & 2.3 & 3 & 10.2 & 10.5 & 10.5 & 0 & 2.857 \\
\hline 11 & 1.5 & 2 & 3 & 10.5 & 10.5 & 10.5 & 0 & 0 \\
\hline 12 & 1 & 1.1 & 5 & 10.5 & 10.5 & 10.5 & 0 & 0 \\
\hline 13 & 1.1 & 1 & 5 & 10.5 & 10.5 & 10.5 & 0 & 0 \\
\hline 14 & 5 & 2 & 1.5 & 10.5 & 10.5 & 10.5 & 0 & 0 \\
\hline 15 & 4 & 3 & 1.5 & 10.5 & 10.5 & 10.5 & 0 & 0 \\
\hline 16 & 4 & 3 & 1.5 & 10.5 & 10.5 & 10.5 & 0 & 0 \\
\hline 17 & 3 & 4 & 1.5 & 10.5 & 10.5 & 10.5 & 0 & 0 \\
\hline 18 & 3 & 4 & 1.5 & 10.5 & 10.5 & 10.5 & 0 & 0 \\
\hline 19 & 2 & 5 & 1.5 & 10.5 & 10.5 & 10.5 & 0 & 0 \\
\hline 20 & 2 & 5 & 1.5 & 10.5 & 10.5 & 10.5 & 0 & 0 \\
\hline 21 & 2.5 & 1 & 3 & 10.5 & 10.5 & 10.5 & 0 & 0 \\
\hline 22 & 4 & 1 & 2.1 & 10.5 & 10.5 & 10.5 & 0 & 0 \\
\hline 23 & 4 & 1 & 2.1 & 10.5 & 10.5 & 10.5 & 0 & 0 \\
\hline 24 & 1.5 & 2 & 3 & 10.5 & 10.5 & 10.5 & 0 & 0 \\
\hline 25 & 3 & 2 & 2.1 & 10.5 & 10.5 & 10.5 & 0 & 0 \\
\hline 26 & 3 & 2 & 2.1 & 10.5 & 10.5 & 10.5 & 0 & 0 \\
\hline 27 & 2 & 3 & 2.1 & 10.5 & 10.5 & 10.5 & 0 & 0 \\
\hline 28 & 2 & 3 & 2.1 & 10.5 & 10.5 & 10.5 & 0 & 0 \\
\hline 29 & 1 & 4 & 2.1 & 10.5 & 10.5 & 10.5 & 0 & 0 \\
\hline 30 & 2 & 1 & 3.5 & 10.5 & 10.5 & 10.5 & 0 & 0 \\
\hline 31 & 2 & 1 & 3.5 & 10.5 & 10.5 & 10.5 & 0 & 0 \\
\hline 32 & 2.5 & 1 & 3 & 10.5 & 10.5 & 10.5 & 0 & 0 \\
\hline 33 & 1 & 2 & 3.5 & 10.5 & 10.5 & 10.5 & 0 & 0 \\
\hline 34 & 1.5 & 2 & 3 & 10.5 & 10.5 & 10.5 & 0 & 0 \\
\hline 35 & 1.1 & 1 & 5 & 10.5 & 10.5 & 10.5 & 0 & 0 \\
\hline 36 & 5 & 2 & 1.5 & 10.5 & 10.5 & 10.5 & 0 & 0 \\
\hline 37 & 4 & 3 & 1.5 & 10.5 & 10.5 & 10.5 & 0 & 0 \\
\hline 38 & 5 & 2 & 1.5 & 10.5 & 10.5 & 10.5 & 0 & 0 \\
\hline 39 & 3 & 4 & 1.5 & 10.5 & 10.5 & 10.5 & 0 & 0 \\
\hline 40 & 4 & 3 & 1.5 & 10.5 & 10.5 & 10.5 & 0 & 0 \\
\hline 41 & 2 & 5 & 1.5 & 10.5 & 10.5 & 10.5 & 0 & 0 \\
\hline 42 & 3 & 4 & 1.5 & 10.5 & 10.5 & 10.5 & 0 & 0 \\
\hline 43 & 2 & 1.5 & 3 & 10.5 & 10.5 & 10.5 & 0 & 0 \\
\hline 44 & 3 & 2 & 2.1 & 10.5 & 10.5 & 10.5 & 0 & 0 \\
\hline 45 & 4 & 1 & 2.1 & 10.5 & 10.5 & 10.5 & 0 & 0 \\
\hline 46 & 1 & 2.5 & 3 & 10.5 & 10.5 & 10.5 & 0 & 0 \\
\hline 47 & 2 & 3 & 2.1 & 10.5 & 10.5 & 10.5 & 0 & 0 \\
\hline 48 & 3 & 2 & 2.1 & 10.5 & 10.5 & 10.5 & 0 & 0 \\
\hline 49 & 1 & 4 & 2.1 & 10.5 & 10.5 & 10.5 & 0 & 0 \\
\hline 50 & 2 & 3 & 2.1 & 10.5 & 10.5 & 10.5 & 0 & 0 \\
\hline 51 & 1 & 4 & 2.1 & 10.5 & 10.5 & 10.5 & 0 & 0 \\
\hline 52 & 1 & 2 & 3.5 & 10.5 & 10.5 & 10.5 & 0 & 0 \\
\hline 53 & 2 & 1 & 3.5 & 10.5 & 10.5 & 10.5 & 0 & 0 \\
\hline 54 & 2 & 1.5 & 3 & 10.5 & 10.5 & 10.5 & 0 & 0 \\
\hline 55 & 1 & 2 & 3.5 & 10.5 & 10.5 & 10.5 & 0 & 0 \\
\hline 56 & 1 & 2.5 & 3 & 10.5 & 10.5 & 10.5 & 0 & 0 \\
\hline 57 & 1 & 1.1 & 5 & 10.5 & 10.5 & 10.5 & 0 & 0 \\
\hline \multicolumn{7}{|c|}{ Average APE } & 0 & 0.150 \\
\hline & & & & & & Max APE & 0 & 2.857 \\
\hline
\end{tabular}


Table 7. 3D solution for $O_{2}$

\begin{tabular}{|c|c|c|c|c|c|c|c|c|}
\hline $\begin{array}{c}\text { Solution } \\
\quad \text { No }\end{array}$ & $A$ & $B$ & $C$ & $\begin{array}{c}\text { Mathematical } \\
\text { Solution } \\
(M S=(A+B) x C)\end{array}$ & $\begin{array}{c}\text { FIL } \\
\text { Solution } \\
(\text { FILS })\end{array}$ & $\begin{array}{l}\text { Desired } \\
\text { Value } \\
(D V)\end{array}$ & $\begin{array}{c}\text { Internal APE } \\
\frac{|F I L S-D V|}{D V} \times 100\end{array}$ & $\begin{array}{c}\text { External APE } \\
\frac{|M S-D V|}{D V} \times 100\end{array}$ \\
\hline & 3.4 & 1.9 & 2 & 10.6 & 10.5 & 10.5 & 0 & 0.952 \\
\hline & 4.1 & 1.9 & 1.9 & 11.4 & 10.5 & 10.5 & 0 & 8.571 \\
\hline & 4.3 & 1.4 & 1.9 & 10.83 & 10.5 & 10.5 & 0 & 3.143 \\
\hline & 4.4 & 1.3 & 1.9 & 10.83 & 10.5 & 10.5 & 0 & 3.143 \\
\hline & 4.9 & 1.1 & 1.9 & 11.4 & 10.5 & 10.5 & 0 & 8.571 \\
\hline & 4.5 & 1.9 & 1.8 & 11.52 & 10.5 & 10.5 & 0 & 9.714 \\
\hline & 5 & 2 & 1.5 & 10.5 & 10.5 & 10.5 & 0 & 0.000 \\
\hline & 2.4 & 2.9 & 2 & 10.6 & 10.5 & 10.5 & 0 & 0.952 \\
\hline & 3.1 & 2.9 & 1.9 & 11.4 & 10.5 & 10.5 & 0 & 8.571 \\
\hline & 3.3 & 2.4 & 1.9 & 10.83 & 10.5 & 10.5 & 0 & 3.143 \\
\hline & 3.4 & 2.3 & 1.9 & 10.83 & 10.5 & 10.5 & 0 & 3.143 \\
\hline & 3.9 & 2.1 & 1.9 & 11.4 & 10.5 & 10.5 & 0 & 8.571 \\
\hline & 3.5 & 2.9 & 1.8 & 11.52 & 10.5 & 10.5 & 0 & 9.714 \\
\hline & 4 & 3 & 1.5 & 10.5 & 10.5 & 10.5 & 0 & 0.000 \\
\hline & 4.1 & 2.3 & 1.7 & 10.88 & 10.5 & 10.5 & 0 & 3.619 \\
\hline & 4.1 & 2.2 & 1.7 & 10.71 & 10.5 & 10.5 & 0 & 2.000 \\
\hline & 4.3 & 2.1 & 1.7 & 10.88 & 10.5 & 10.5 & 0 & 3.619 \\
\hline & 4.2 & 2.1 & 1.7 & 10.71 & 10.5 & 10.5 & 0 & 2.000 \\
\hline & 4 & 3 & 1.5 & 10.5 & 10.5 & 10.5 & 0 & 0.000 \\
\hline & 4.2 & 2.8 & 1.5 & 10.5 & 10.5 & 10.5 & 0 & 0.000 \\
\hline & 4.5 & 2.5 & 1.5 & 10.5 & 10.5 & 10.5 & 0 & 0.000 \\
\hline & 4.7 & 2.3 & 1.5 & 10.5 & 10.5 & 10.5 & 0 & 0.000 \\
\hline & 4.9 & 2.1 & 1.5 & 10.5 & 10.5 & 10.5 & 0 & 0.000 \\
\hline & 5 & 2 & 1.5 & 10.5 & 10.5 & 10.5 & 0 & 0.000 \\
\hline & 1.4 & 3.9 & 2 & 10.6 & 10.5 & 10.5 & 0 & 0.952 \\
\hline & 2.1 & 3.9 & 1.9 & 11.4 & 10.5 & 10.5 & 0 & 8.571 \\
\hline & 2.3 & 3.4 & 1.9 & 10.83 & 10.5 & 10.5 & 0 & 3.143 \\
\hline & 2.4 & 3.3 & 1.9 & 10.83 & 10.5 & 10.5 & 0 & 3.143 \\
\hline & 2.9 & 3.1 & 1.9 & 11.4 & 10.5 & 10.5 & 0 & 8.571 \\
\hline & 2.5 & 3.9 & 1.8 & 11.52 & 10.5 & 10.5 & 0 & 9.714 \\
\hline & 3 & 4 & 1.5 & 10.5 & 10.5 & 10.5 & 0 & 0.000 \\
\hline & 3.1 & 3.3 & 1.7 & 10.88 & 10.5 & 10.5 & 0 & 3.619 \\
\hline & 3.1 & 3.2 & 1.7 & 10.71 & 10.5 & 10.5 & 0 & 2.000 \\
\hline & 3.3 & 3.1 & 1.7 & 10.88 & 10.5 & 10.5 & 0 & 3.619 \\
\hline & 3.2 & 3.1 & 1.7 & 10.71 & 10.5 & 10.5 & 0 & 2.000 \\
\hline & 3 & 4 & 1.5 & 10.5 & 10.5 & 10.5 & 0 & 0.000 \\
\hline & 3.2 & 3.8 & 1.5 & 10.5 & 10.5 & 10.5 & 0 & 0.000 \\
\hline & 3.5 & 3.5 & 1.5 & 10.5 & 10.5 & 10.5 & 0 & 0.000 \\
\hline & 3.7 & 3.3 & 1.5 & 10.5 & 10.5 & 10.5 & 0 & 0.000 \\
\hline & 3.9 & 3.1 & 1.5 & 10.5 & 10.5 & 10.5 & 0 & 0.000 \\
\hline & 4 & 3 & 1.5 & 10.5 & 10.5 & 10.5 & 0 & 0.000 \\
\hline & 4 & 3 & 1.5 & 10.5 & 10.5 & 10.5 & 0 & 0.000 \\
\hline & 4.1 & 3.9 & 1.2 & 9.6 & 10.5 & 10.5 & 0 & 8.571 \\
\hline & 4.9 & 3.1 & 1.2 & 9.6 & 10.5 & 10.5 & 0 & 8.571 \\
\hline & 1.1 & 4.9 & 1.9 & 11.4 & 10.5 & 10.5 & 0 & 8.571 \\
\hline & 1.3 & 4.4 & 1.9 & 10.83 & 10.5 & 10.5 & 0 & 3.143 \\
\hline & 1.4 & 4.3 & 1.9 & 10.83 & 10.5 & 10.5 & 0 & 3.143 \\
\hline & 1.9 & 4.1 & 1.9 & 11.4 & 10.5 & 10.5 & 0 & 8.571 \\
\hline & 1.5 & 4.9 & 1.8 & 11.52 & 10.5 & 10.5 & 0 & 9.714 \\
\hline & 2 & 5 & 1.5 & 10.5 & 10.5 & 10.5 & 0 & 0.000 \\
\hline & 2.1 & 4.3 & 1.7 & 10.88 & 10.5 & 10.5 & 0 & 3.619 \\
\hline & 2.1 & 4.2 & 1.7 & 10.71 & 10.5 & 10.5 & 0 & 2.000 \\
\hline & 2.3 & 4.1 & 1.7 & 10.88 & 10.5 & 10.5 & 0 & 3.619 \\
\hline & 2.2 & 4.1 & 1.7 & 10.71 & 10.5 & 10.5 & 0 & 2.000 \\
\hline & 2 & 5 & 1.5 & 10.5 & 10.5 & 10.5 & 0 & 0.000 \\
\hline & 2.2 & 4.8 & 1.5 & 10.5 & 10.5 & 10.5 & 0 & 0.000 \\
\hline & 2.5 & 4.5 & 1.5 & 10.5 & 10.5 & 10.5 & 0 & 0.000 \\
\hline & 2.7 & 4.3 & 1.5 & 10.5 & 10.5 & 10.5 & 0 & 0.000 \\
\hline & 2.9 & 4.1 & 1.5 & 10.5 & 10.5 & 10.5 & 0 & 0.000 \\
\hline & 3 & 4 & 1.5 & 10.5 & 10.5 & 10.5 & 0 & 0.000 \\
\hline & 3 & 4 & 1.5 & 10.5 & 10.5 & 10.5 & 0 & 0.000 \\
\hline & 3.1 & 4.9 & 1.2 & 9.6 & 10.5 & 10.5 & 0 & 8.571 \\
\hline & 3.9 & 4.1 & 1.2 & 9.6 & 10.5 & 10.5 & 0 & 8.571 \\
\hline & 4.5 & 4.5 & 1.1 & 9.9 & 10.5 & 10.5 & 0 & 5.714 \\
\hline & 1.5 & 2 & 3 & 10.5 & 10.5 & 10.5 & 0 & 0.000 \\
\hline & 2 & 1.5 & 3 & 10.5 & 10.5 & 10.5 & 0 & 0.000 \\
\hline & 2 & 1.5 & 3 & 10.5 & 10.5 & 10.5 & 0 & 0.000 \\
\hline & 2.1 & 1.3 & 3 & 10.2 & 10.5 & 10.5 & 0 & 2.857 \\
\hline & 2.5 & 1 & 3 & 10.5 & 10.5 & 10.5 & 0 & 0.000 \\
\hline & 2.5 & 1.7 & 2.7 & 11.34 & 10.5 & 10.5 & 0 & 8.000 \\
\hline
\end{tabular}


Table 7. Continued

\begin{tabular}{|c|c|c|c|c|c|c|c|c|}
\hline $\begin{array}{l}\text { Solution } \\
\quad \text { No }\end{array}$ & $A$ & $B$ & $C$ & $\begin{array}{c}\text { Mathematical } \\
\text { Solution } \\
(M S=(A+B) x C)\end{array}$ & $\begin{array}{c}\text { FIL } \\
\text { Solution } \\
\text { (FILS) }\end{array}$ & $\begin{array}{l}\text { Desired } \\
\text { Value } \\
(D V)\end{array}$ & $\begin{array}{c}\text { Internal APE } \\
\frac{|F I L S-D V|}{D V} \times 100\end{array}$ & $\begin{array}{c}\text { External APE } \\
\frac{|M S-D V|}{D V} \times 100\end{array}$ \\
\hline & 2.5 & 1.6 & 2.7 & 11.07 & 10.5 & 10.5 & 0 & 5.429 \\
\hline & 2.7 & 1.5 & 2.7 & 11.34 & 10.5 & 10.5 & 0 & 8.000 \\
\hline & 2.5 & 1.5 & 2.7 & 10.8 & 10.5 & 10.5 & 0 & 2.857 \\
\hline & 2.6 & 1.7 & 2.6 & 11.18 & 10.5 & 10.5 & 0 & 6.476 \\
\hline & 2.7 & 1.6 & 2.6 & 11.18 & 10.5 & 10.5 & 0 & 6.476 \\
\hline & 2.3 & 1.9 & 2.5 & 10.5 & 10.5 & 10.5 & 0 & 0.000 \\
\hline & 2.9 & 1.3 & 2.5 & 10.5 & 10.5 & 10.5 & 0 & 0.000 \\
\hline & 2.4 & 1.9 & 2.4 & 10.32 & 10.5 & 10.5 & 0 & 1.714 \\
\hline & 2.7 & 1.9 & 2.3 & 10.58 & 10.5 & 10.5 & 0 & 0.762 \\
\hline & 2.9 & 1.7 & 2.3 & 10.58 & 10.5 & 10.5 & 0 & 0.762 \\
\hline & 3 & 2 & 2.1 & 10.5 & 10.5 & 10.5 & 0 & 0.000 \\
\hline & 3.1 & 1.1 & 2.2 & 9.24 & 10.5 & 10.5 & 0 & 12.000 \\
\hline & 3 & 2 & 2.1 & 10.5 & 10.5 & 10.5 & 0 & 0.000 \\
\hline & 4 & 1 & 2.1 & 10.5 & 10.5 & 10.5 & 0 & 0.000 \\
\hline & 3.4 & 1.9 & 2 & 10.6 & 10.5 & 10.5 & 0 & 0.952 \\
\hline & 4 & 1 & 2.1 & 10.5 & 10.5 & 10.5 & 0 & 0.000 \\
\hline & 1 & 2.5 & 3 & 10.5 & 10.5 & 10.5 & 0 & 0.000 \\
\hline & 1.1 & 2.3 & 3 & 10.2 & 10.5 & 10.5 & 0 & 2.857 \\
\hline & 1.5 & 2 & 3 & 10.5 & 10.5 & 10.5 & 0 & 0.000 \\
\hline & 1.5 & 2.7 & 2.7 & 11.34 & 10.5 & 10.5 & 0 & 8.000 \\
\hline & 1.5 & 2.6 & 2.7 & 11.07 & 10.5 & 10.5 & 0 & 5.429 \\
\hline & 1.7 & 2.5 & 2.7 & 11.34 & 10.5 & 10.5 & 0 & 8.000 \\
\hline & 1.5 & 2.5 & 2.7 & 10.8 & 10.5 & 10.5 & 0 & 2.857 \\
\hline & 1.6 & 2.7 & 2.6 & 11.18 & 10.5 & 10.5 & 0 & 6.476 \\
\hline & 1.7 & 2.6 & 2.6 & 11.18 & 10.5 & 10.5 & 0 & 6.476 \\
\hline & 1.3 & 2.9 & 2.5 & 10.5 & 10.5 & 10.5 & 0 & 0.000 \\
\hline & 1.9 & 2.3 & 2.5 & 10.5 & 10.5 & 10.5 & 0 & 0.000 \\
\hline & 1.4 & 2.9 & 2.4 & 10.32 & 10.5 & 10.5 & 0 & 1.714 \\
\hline & 1.7 & 2.9 & 2.3 & 10.58 & 10.5 & 10.5 & 0 & 0.762 \\
\hline & 1.9 & 2.7 & 2.3 & 10.58 & 10.5 & 10.5 & 0 & 0.762 \\
\hline & 2 & 3 & 2.1 & 10.5 & 10.5 & 10.5 & 0 & 0.000 \\
\hline & 2.1 & 2.1 & 2.2 & 9.24 & 10.5 & 10.5 & 0 & 12.000 \\
\hline & 2 & 3 & 2.1 & 10.5 & 10.5 & 10.5 & 0 & 0.000 \\
\hline & 3 & 2 & 2.1 & 10.5 & 10.5 & 10.5 & 0 & 0.000 \\
\hline & 2.4 & 2.9 & 2 & 10.6 & 10.5 & 10.5 & 0 & 0.952 \\
\hline & 3 & 2 & 2.1 & 10.5 & 10.5 & 10.5 & 0 & 0.000 \\
\hline & 1.1 & 3.1 & 2.2 & 9.24 & 10.5 & 10.5 & 0 & 12.000 \\
\hline & 1 & 4 & 2.1 & 10.5 & 10.5 & 10.5 & 0 & 0.000 \\
\hline & 2 & 3 & 2.1 & 10.5 & 10.5 & 10.5 & 0 & 0.000 \\
\hline & 1.4 & 3.9 & 2 & 10.6 & 10.5 & 10.5 & 0 & 0.952 \\
\hline & 2 & 3 & 2.1 & 10.5 & 10.5 & 10.5 & 0 & 0.000 \\
\hline & 1 & 4 & 2.1 & 10.5 & 10.5 & 10.5 & 0 & 0.000 \\
\hline & 1.3 & 1.4 & 3.8 & 10.26 & 10.5 & 10.5 & 0 & 2.286 \\
\hline & 1.4 & 1.3 & 3.8 & 10.26 & 10.5 & 10.5 & 0 & 2.286 \\
\hline & 1 & 2 & 3.5 & 10.5 & 10.5 & 10.5 & 0 & 0.000 \\
\hline & 1.2 & 1.8 & 3.5 & 10.5 & 10.5 & 10.5 & 0 & 0.000 \\
\hline & 1.5 & 1.5 & 3.5 & 10.5 & 10.5 & 10.5 & 0 & 0.000 \\
\hline & 1.8 & 1.2 & 3.5 & 10.5 & 10.5 & 10.5 & 0 & 0.000 \\
\hline & 2 & 1 & 3.5 & 10.5 & 10.5 & 10.5 & 0 & 0.000 \\
\hline & 1.8 & 1.5 & 3.2 & 10.56 & 10.5 & 10.5 & 0 & 0.571 \\
\hline & 1.5 & 2 & 3 & 10.5 & 10.5 & 10.5 & 0 & 0.000 \\
\hline & 2 & 1.5 & 3 & 10.5 & 10.5 & 10.5 & 0 & 0.000 \\
\hline & 2 & 1 & 3.5 & 10.5 & 10.5 & 10.5 & 0 & 0.000 \\
\hline & 2 & 1.5 & 3 & 10.5 & 10.5 & 10.5 & 0 & 0.000 \\
\hline & 2.1 & 1.3 & 3 & 10.2 & 10.5 & 10.5 & 0 & 2.857 \\
\hline & 2.5 & 1 & 3 & 10.5 & 10.5 & 10.5 & 0 & 0.000 \\
\hline & 1 & 2 & 3.5 & 10.5 & 10.5 & 10.5 & 0 & 0.000 \\
\hline & 1 & 2.5 & 3 & 10.5 & 10.5 & 10.5 & 0 & 0.000 \\
\hline & 1.1 & 2.3 & 3 & 10.2 & 10.5 & 10.5 & 0 & 2.857 \\
\hline & 1.5 & 2 & 3 & 10.5 & 10.5 & 10.5 & 0 & 0.000 \\
\hline & 1 & 1.1 & 5 & 10.5 & 10.5 & 10.5 & 0 & 0.000 \\
\hline & 1.1 & 1 & 5 & 10.5 & 10.5 & 10.5 & 0 & 0.000 \\
\hline \multicolumn{7}{|c|}{ Average APE } & 0 & 2.618 \\
\hline & & & & & & Max APE & 0 & 12.000 \\
\hline
\end{tabular}


In this sample problem, the effects of the sensitivity in membership iterations, the analysis dimension used in the analyzes and the amount of acceptable error for the desired output on internal error and external error in fuzzy inverse logic analysis were also investigated. In order to that the results obtained from these studies do not take too much place in the article, it is preferred to present them in the following part of the article with the help of graphics rather than in tables as above.

2D analyses with \% 0 acceptable error were performed to reveal the effect of the change in membership sensitivity on the number of solutions and on the solution errors in FIL computations. As a result of the analysis; The number of solutions obtained depending on the membership sensitivity in the iterations within the FIL operations are given in Figure 5. As can be understood from this figure, the smaller change in the membership value in membership iterations, that is, the higher the sensitivity, the more solutions can be obtained. As the sensitivity decreased, the number of solutions decreased. This is an expected result and a point to be considered in FIL analysis.

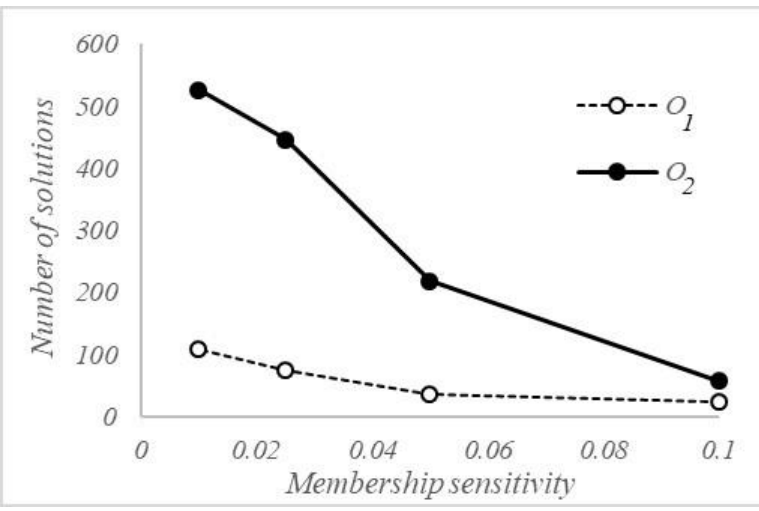

Figure 5. Number of solutions depending on the membership sensitivity

The effects of different membership sensitivities on internal errors (maximum internal error and average internal error) between output values obtained in fuzzy solutions and desired output values are shown in Figure 6a. Similarly, the effects of different membership sensitivities on external errors (maximum internal error and average internal error) between mathematical outputs and targeted desired output values are graphically shown in Figure $6 \mathrm{~b}$. As it can be understood from Figure $6 a$ and Figure $6 \mathrm{~b}$ that the analyzes with very high sensitivity produced bigger internal errors and externals error. This shows that studying with extreme sensitivity in FIL computations has not always produce good results.

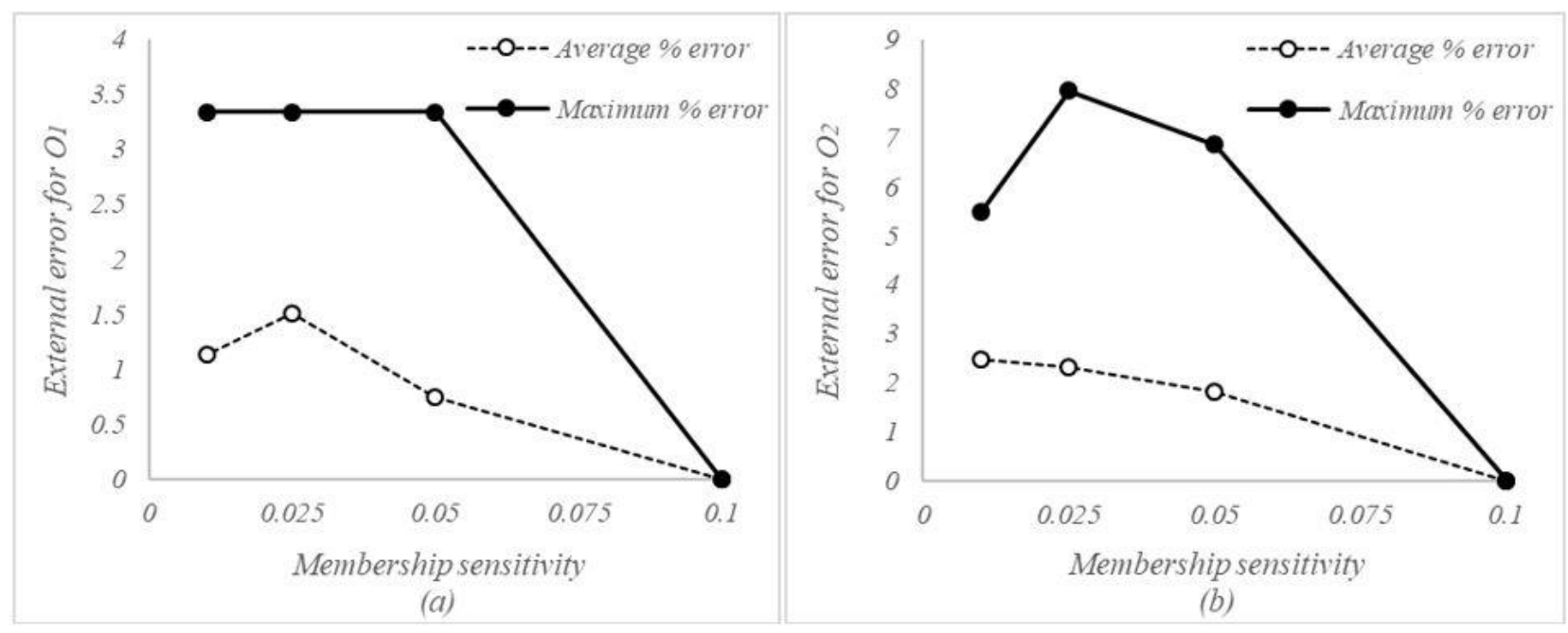

Figure 6. Average and maximum external error variation in $\mathrm{O}_{1}$ and $\mathrm{O}_{2}$ outputs depending on the membership sensitivity.

In addition to all these, working with extreme sensitivity also causes too much iteration and prolonging the solution time in FIL computations. Therefore, considering all the graphs of Figure 4, Figure $5 \mathrm{a}$ and Figure $5 \mathrm{~b}$, it can be said that 0.1 value for the membership sensitivity appropriate for this example problem. This does not mean that membership sensitivity values less than 0.1 cannot be used in FIL computations in this example.

Because, if the graphs are examined carefully, it can be seen that the absolute average \% error in the solutions produced by FIL is within acceptable limits even for high sensitivity. The fact that the 
maximum error values at the same level of sensitivity are different (greater) than the average error indicates that the FIL may also produce erroneous results at these levels of sensitivity and the user should be careful. Here, it is important to underline that it is not the FIL method or the sensitivity value that caused the error, but the inadequate and poor modelled of the FL model used. Especially if the local minimum and local maximum solution regions of the problem are not modeled well and sensitively, greater errors can be seen in FL and therefore in FIL computations. On the other hand, it is a fact that many studies are needed to reveal whether there is a general approach in order to determine the sensitivity of membership correctly and how it should be.

An effect of membership sensitivity on internal errors has not been determined. Because all internal errors were obtained as zero. This result can be interpreted as, at least in this sample problem, membership sensitivity has no effect on internal errors. In order to generalize this result, FIL needs to be applied to many problems.
The effect of the acceptable error amount for the desired output on the number of solutions is given in Figure 7 in this problem. As can be easily seen from this figure, as the acceptable error level increases for the desired output values, the number of solutions obtained from FIL also increases. This is because solutions that cannot be obtained at a smaller error level with small differences can also be obtained at a bigger acceptable error level, and the problem has other solutions in the larger acceptable error limits.

The effect of the acceptable error amount for the desired output on the internal error and external error values of the $O_{l}$ output is given in Figure 8a and Figure $8 \mathrm{~b}$, and the effect on the internal error and external error values of the $\mathrm{O}_{2}$ output is given in Figure 9a and Figure 9b, respectively. As it can be understood from these Figures, as the acceptable error level for the desired output increases, the amount of internal error and external error calculated as a result of FIL analysis naturally increases. It is worth mentioning that the value of the amount of internal errors and external errors is of great importance whether the FL model used in the FIL is well designed or not.

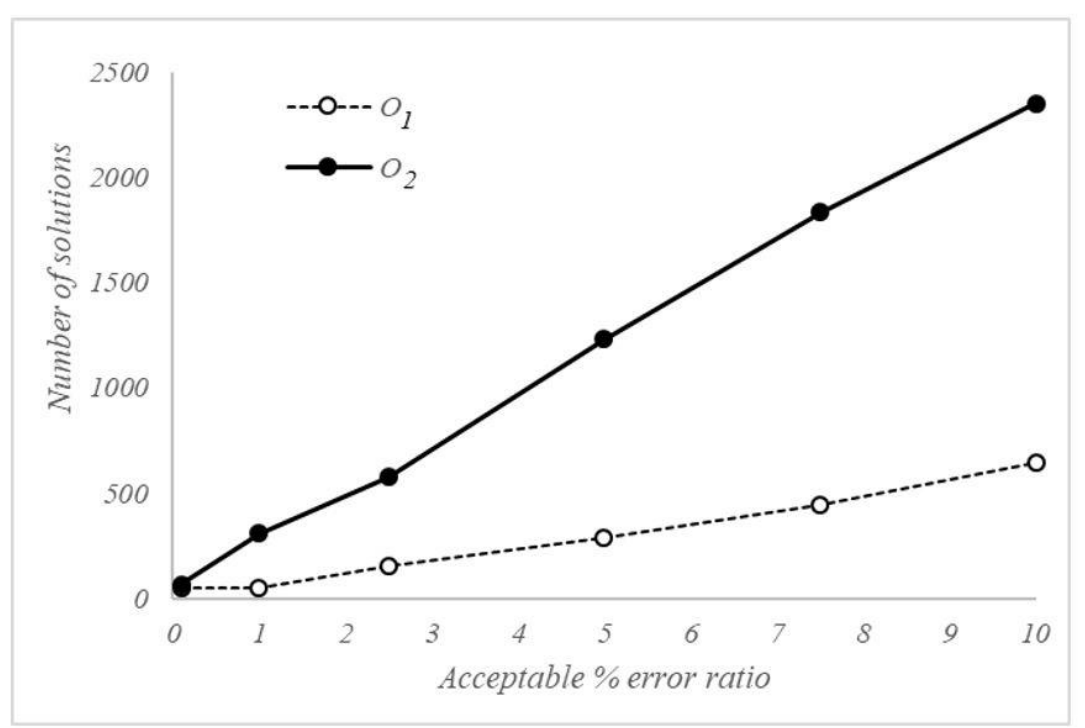

Figure 7. The number of solutions obtained depending on the different acceptable error ratios for $\mathrm{O}_{1}$ and $\mathrm{O}_{2}$ outputs. 


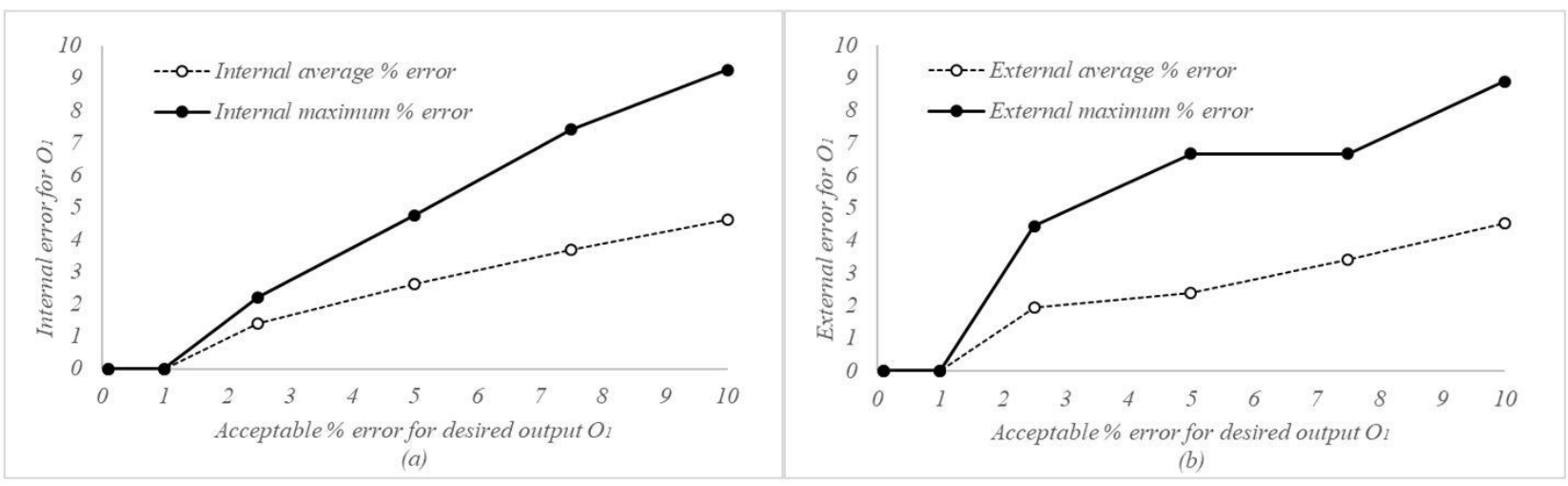

Figure 8. Variations of internal and external $\%$ errors with acceptable $\%$ error for $\mathrm{O}_{1}$ output
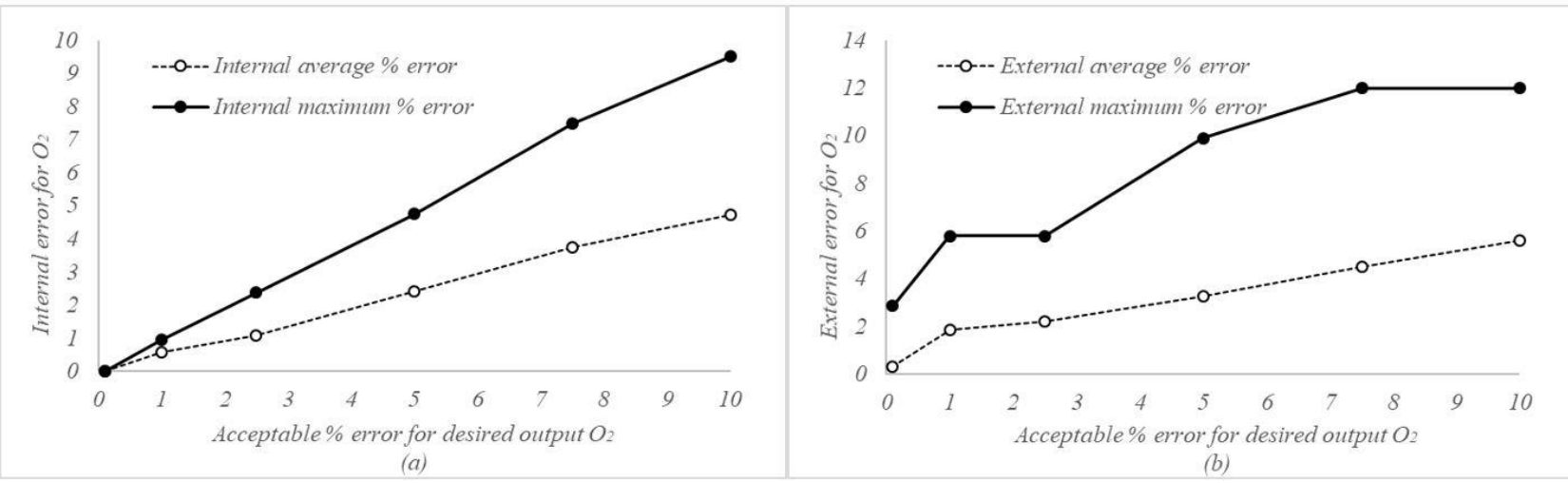

Figure 9. Variations of internal and external $\%$ errors with acceptable $\%$ error for $\mathrm{O}_{2}$ output

Depending on the analysis dimension, variation in the number of solutions and variations in average and maximum external error values were also investigated for this example, and they are given in Figure 10 and Figure $11 \mathrm{a}$ and Figure $11 \mathrm{~b}$ respectively. These investigations were presented by graphics for only external errors because of the internal errors were obtained as 0 for all analysis dimensions.

Figure 10 clearly shows that as the number of dimensions increases, the number of solutions increases. This is an expected result. In Figure 11 a and Figure $11 \mathrm{~b}$, it is seen that output errors increase significantly with the increase in analysis dimension. After 1D, 2D and 3D analyzes, although there were significant increases in external error values as the dimension increased, the average external error values remained within acceptable limits for both outputs. However, the maximum external error value has reached or exceeded the acceptable limits.

In the light of all these, it can be said that increasing the analysis dimension causes a serious increase in the amount of external errors. The reason for this is that fuzzy modeling errors in each dimension affect each other and cause much larger errors. If it is required to express more clearly, not creating a fuzzy model with sufficient sensitivity and accuracy led to bigger external errors.

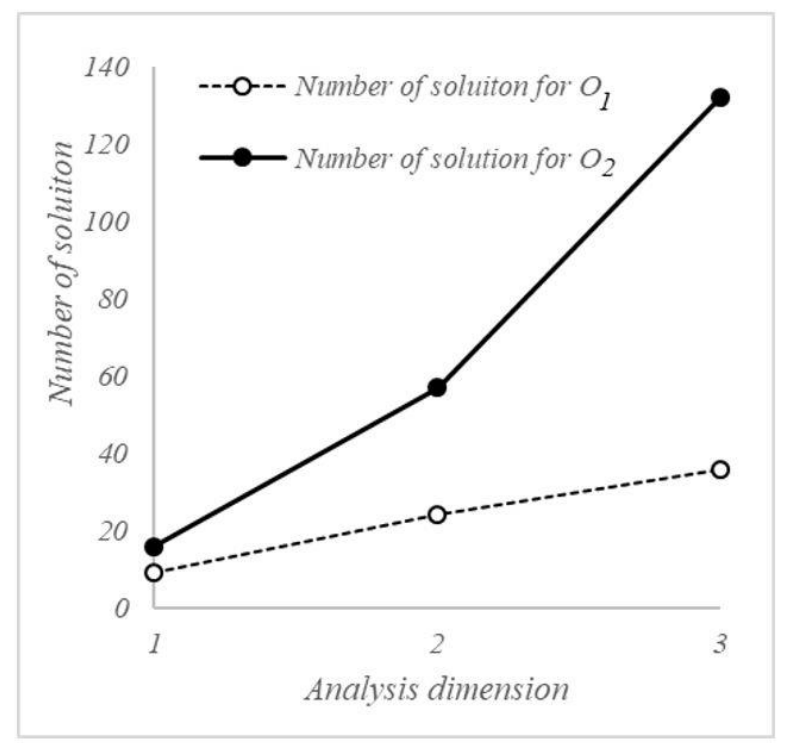

Figure 10. Number of solutions depending on analysis dimension 

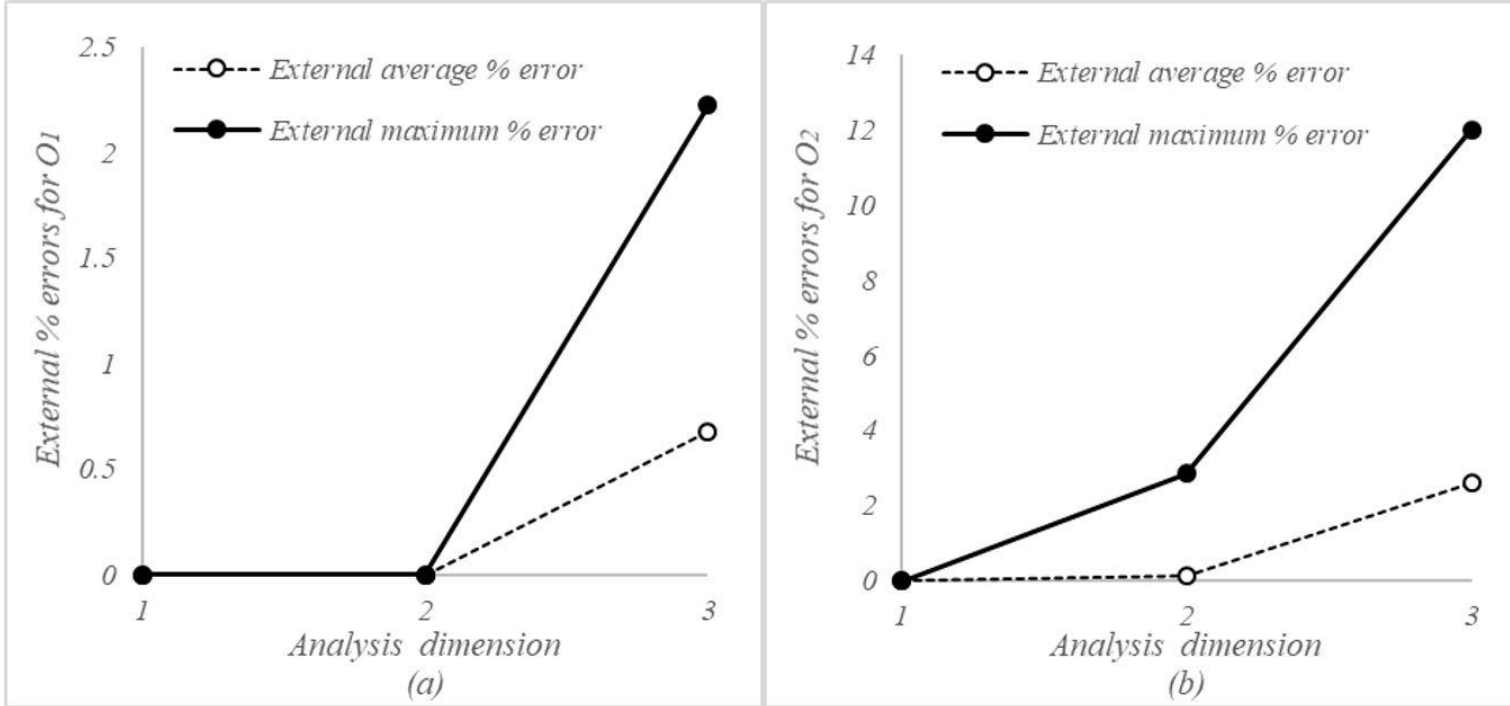

Figure 11. Variation of External \% errors depending on analysis dimension for $\mathrm{O}_{1}$ and $\mathrm{O}_{2}$

On the other hand, it is very natural to have internal error values as 0 . Because, FIL computations are configured to obtain input parameters with $0 \%$ error in this example. In other words, regardless of the errors in the fuzzy model, even if the error in a fuzzy logic model is not sensitive enough, FIL method focuses on computing the input parameters with $0 \%$ error to reach the desired output value. This situation actually provides a great advantage for control problems. On the other hand, a serious increase in external errors depending on analysis dimension can constitute a significant risk for designs in engineering problems. The only way to prevent this risk is to construct very sensitive fuzzy models and to seriously test them.

If it needs to evaluate this situation from the opposite perspective, one way to find out if a fuzzy model has been constituted well may be to apply the FIL method on this FL model.

2.2. Application of the FIL method on problem-2 (Designing of a cantilever beam according to the ASD method under bending moment and shear forces by FIL method)

Bending moment and shear force diagrams drawn for a cantilever beam loaded with two concentrated loads are presented in Figure 12. In the light of the information given in Figure 12, design this beam as I shaped section by using St 37 graded steel material $\left(\sigma_{\mathrm{em}}=141 \mathrm{~N} / \mathrm{mm}^{2}\right.$ and $\left.\tau_{\mathrm{em}}=82 \mathrm{kN}\right)$ accordance with the ASD method.
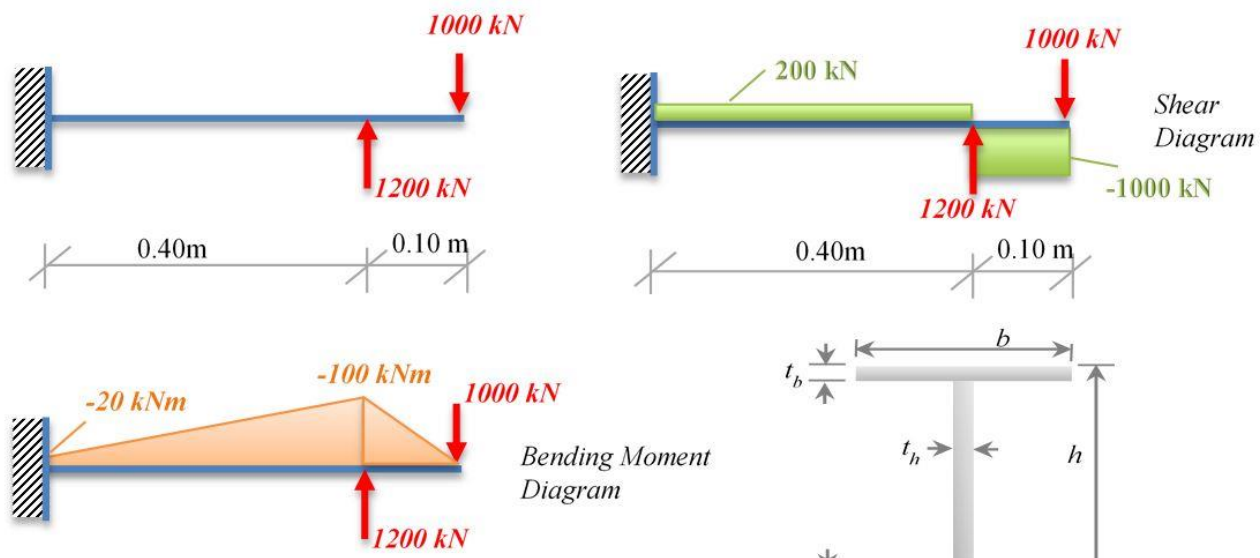

$0.40 \mathrm{~m}$
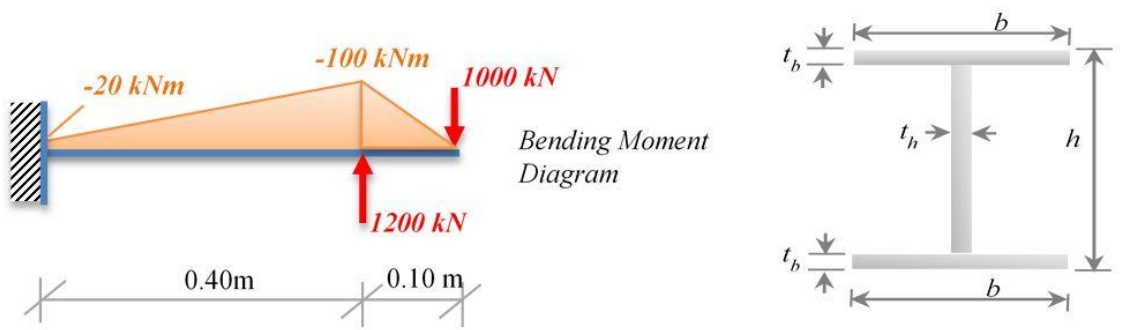

Figure 12. An I shaped cantilever beam subjected two concentrated loads 


\subsubsection{Mechanical design}

As seen from Figure 12 the maximum absolute bending moment values is $\mathrm{M}_{\max }=100 \mathrm{kNm}$ and the maximum absolute shear force value is $\mathrm{V}_{\max }=1000$ $\mathrm{kN}$ on this beam. Therefore, a design that can safely bear both bending and shearing effects is required.

\subsubsection{Design for $V_{\max }=1000 \mathrm{kN}$}

$$
\begin{aligned}
\tau_{e m} \leq \frac{V_{\max }}{F} \rightarrow F & =\frac{V_{\text {max }}}{\tau_{\text {em }}} \rightarrow F=\frac{1000 \times 10^{3} \mathrm{~N}}{82 \mathrm{~N} / \mathrm{mm}^{2}} \\
\rightarrow F & =12195.122 \mathrm{~mm}^{2}
\end{aligned}
$$

In the mechanical design, after the minimum area that can bear the effect of the shear force is determined as $\mathrm{F}=12195.122 \mathrm{~mm}^{2}$ as above, the cross section dimensions that will provide this area are tried to be determined by trial and error computations or a profile section is selected from the ready-made profile tables. As an example, the cross section dimensions can be determined as $\mathrm{b}=80 \mathrm{~mm}, \mathrm{t}_{\mathrm{b}}=20 \mathrm{~mm}, \mathrm{~h}=300 \mathrm{~mm}, \mathrm{t}_{\mathrm{h}}=30 \mathrm{~mm}$ for $\mathrm{F}=12200 \mathrm{~mm}^{2}$ after a lot of trial and error computations.

\subsubsection{Design for $M_{\max }=100 \mathrm{kNm}$}

$$
\begin{aligned}
\sigma_{\text {em }} \leq \frac{M_{\text {max }}}{W} \rightarrow & W=\frac{M_{\text {max }}}{\sigma_{\text {em }}} \rightarrow F \\
& =\frac{100 \times 10^{6} \mathrm{Nmm}}{141 \mathrm{~N} / \mathrm{mm}^{2}} \rightarrow W \\
& =709219.858 \mathrm{~mm}^{3}
\end{aligned}
$$

Here $\mathrm{W}$ is elastic section modulus and can be calculated by $\mathrm{W}=\mathrm{I} / \mathrm{d}$ (I: moment of inertia and d: the distance of the farthest point on a cross section to center of gravity of the section).

In the mechanical design, after the elastic section modulus for $M=100 \mathrm{kNm}$ is determined as $\mathrm{W}=$

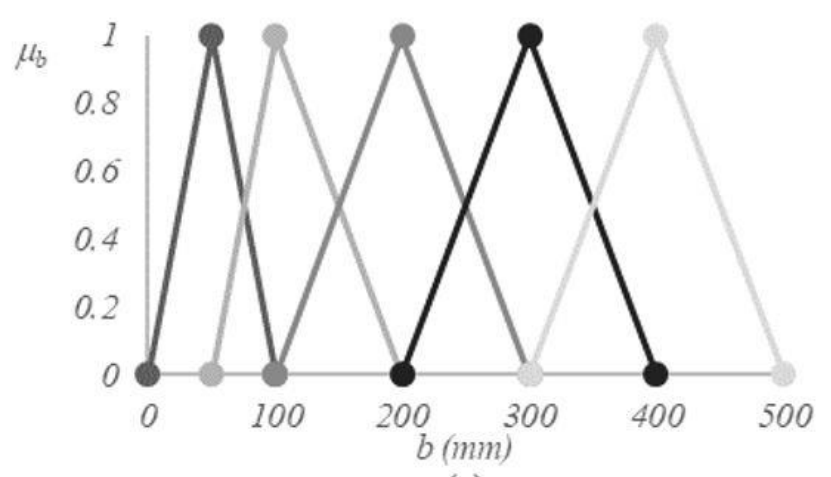

(a)
$709219.858 \mathrm{~mm}^{3}$ as above, the cross section dimensions that will provide this area are tried to be determined by trial and error computations or a profile section is selected from the ready-made profile tables. As an example, the cross section dimensions can be determined as $\mathrm{b}=80 \mathrm{~mm}, \mathrm{t}_{\mathrm{b}}=20$ $\mathrm{mm}, \mathrm{h}=300 \mathrm{~mm}, \mathrm{t}_{\mathrm{h}}=30 \mathrm{~mm}$ for $\mathrm{W}=711778 \mathrm{~mm}^{3}$ after a lot of trial and error computations.

\subsubsection{Solution by FIL}

\subsubsection{Constitution of FL model for problem-2}

For this design problem, a FL model is constituted as described below. Since the design is going to be performed according to the known steel grade and I-shaped cross section of the beam, there are 4 parameters to be determined for design in this problem. These are $b, t_{b}, h$ and $t_{h}$ the parameters that define the beam cross section.

In this problem, the FL model was constituted in such a way that these four parameters constitute the input parameters of the model and the $\mathrm{M}$ bending moment and V shear force constitute the output parameters. Since the input parameters are the same for both outputs, there is no need to constitute two different FL separate models. During the constitution of the FL model, fuzzy sets belong to input and output parameters were constituted by using triangle membership functions. In Figure 13a, Figure 13b, Figure 14a and Figure 14b, fuzzy sets for input parameters of $b, t_{b}, h$ and $t_{h}$ are given respectively. For the M and V outputs, 588 and 69 fuzzy sets were constituted, respectively. These fuzzy sets are constituted from $\mathrm{M}$ and $\mathrm{T}$ values calculated with the help of structural mechanics analyses for all combinations of 4 input parameters. Since a large number of fuzzy sets belonging to these two outputs were constituted, they could not be given as tables and graphics in this study.

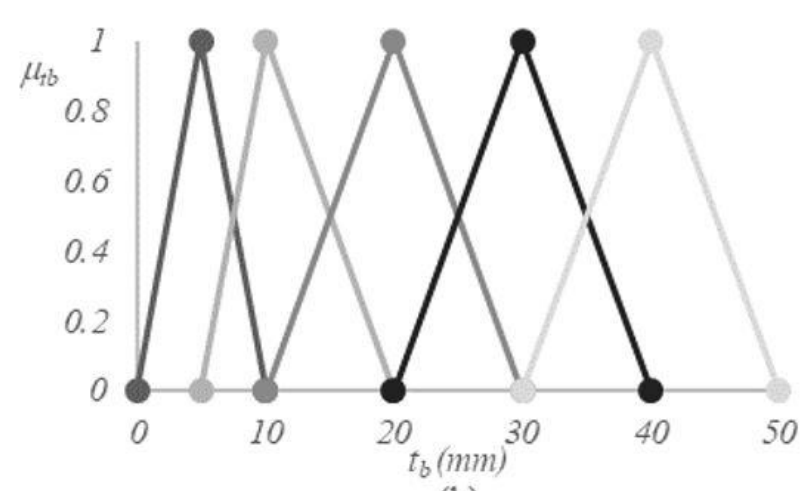

(b)

Figure 13. Fuzzy sets for $b$ and $t_{b}$ parameters 


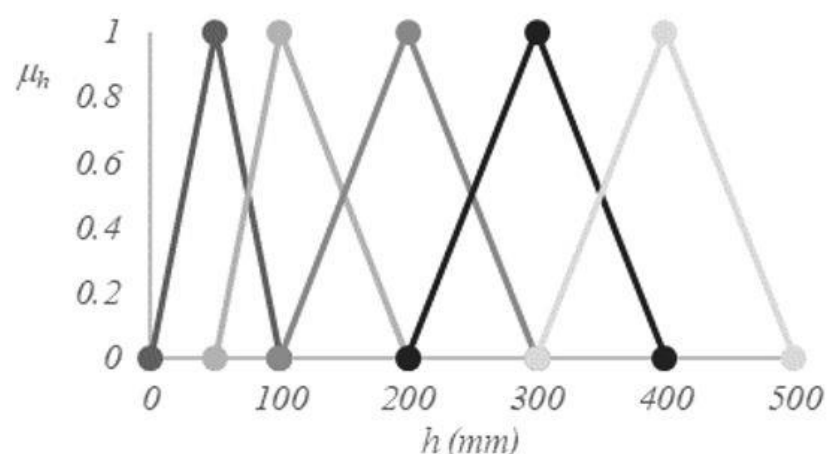

(a)

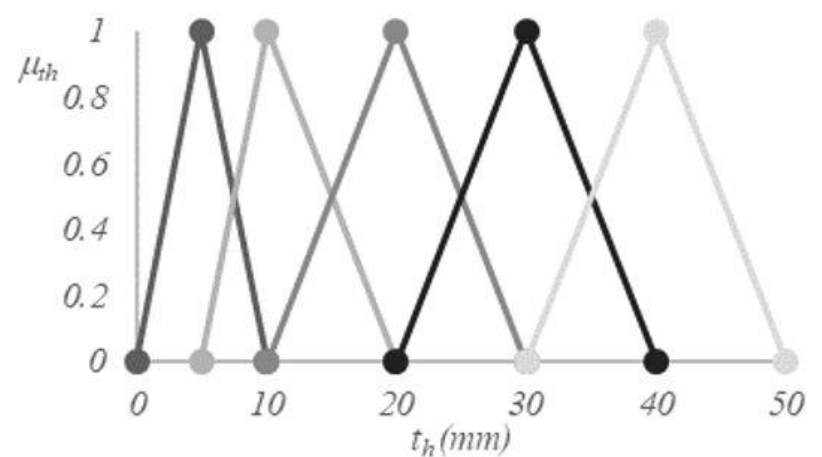

(b)

Figure 14. Fuzzy sets for $h$ and $t_{h}$ parameters

In this problem, 625 rules were constituted for each of the M and V outputs. The WAM method was used for de-fuzzification in the constituted fuzzy model. The model is tested for 81 different samples given in Table 8 for each output. While correlation was $\mathrm{R}=0.9996$ and correlation coefficient was $\mathrm{R}^{2}$ $=0.9993$ for the $\mathrm{M}$ output in the test results, the correlation and the correlation coefficient were obtained as $\mathrm{R}=0.9999$ and $\mathrm{R}^{2}=0.9999$ respectively for $\mathrm{V}$ output. For the $\mathrm{M}$ and $\mathrm{V}$ output, the absolute average percent error was calculated as 0.724 and 0.256 , respectively, and the absolute maximum percent error was calculated as 3.557 and 0.811 , respectively.

Table 8. Test data for FL in problem 2

\begin{tabular}{|c|c|c|c|c|c|c|c|c|c|c|}
\hline \multirow[b]{2}{*}{ No } & \multicolumn{4}{|c|}{ Variable Parameters } & \multicolumn{2}{|c|}{ Mathemetical Solution } & \multicolumn{2}{|c|}{ FIL Solution } & \multicolumn{2}{|c|}{ Absolute Percent Error } \\
\hline & $b$ & $t_{b}$ & $h$ & $t_{h}$ & $M$ & $V$ & $M$ & $V$ & $E_{M}$ & $E_{V}$ \\
\hline 1 & 150 & 15 & 150 & 15 & 42.765 & 553.5 & 42.994 & 549.016 & 0.535 & 0.810 \\
\hline 2 & 150 & 15 & 150 & 25 & 45.473 & 676.5 & 46.451 & 675.503 & 2.151 & 0.147 \\
\hline 3 & 150 & 15 & 150 & 35 & 48.180 & 799.5 & 49.820 & 795.514 & 3.404 & 0.499 \\
\hline 4 & 150 & 15 & 250 & 15 & 85.189 & 676.5 & 85.076 & 675.503 & 0.133 & 0.147 \\
\hline 5 & 150 & 15 & 250 & 25 & 95.199 & 881.5 & 95.911 & 883.493 & 0.748 & 0.226 \\
\hline 6 & 150 & 15 & 250 & 35 & 105.208 & 1086.5 & 106.532 & 1084.507 & 1.259 & 0.183 \\
\hline 7 & 150 & 15 & 350 & 15 & 134.794 & 799.5 & 134.715 & 795.514 & 0.059 & 0.499 \\
\hline 8 & 150 & 15 & 350 & 25 & 156.795 & 1086.5 & 157.480 & 1084.507 & 0.437 & 0.183 \\
\hline 9 & 150 & 15 & 350 & 35 & 178.797 & 1373.5 & 180.034 & 1369.514 & 0.692 & 0.290 \\
\hline 10 & 150 & 25 & 150 & 15 & 58.163 & 799.5 & 58.766 & 799.002 & 1.038 & 0.062 \\
\hline 11 & 150 & 25 & 150 & 25 & 59.729 & 922.5 & 61.079 & 921.005 & 2.260 & 0.162 \\
\hline 12 & 150 & 25 & 150 & 35 & 61.296 & 1045.5 & 63.250 & 1042.012 & 3.189 & 0.334 \\
\hline 13 & 150 & 25 & 250 & 15 & 118.793 & 922.5 & 118.781 & 921.005 & 0.010 & 0.162 \\
\hline 14 & 150 & 25 & 250 & 25 & 126.313 & 1127.5 & 127.173 & 1125.009 & 0.681 & 0.221 \\
\hline 15 & 150 & 25 & 250 & 35 & 133.833 & 1332.5 & 135.274 & 1327.019 & 1.077 & 0.411 \\
\hline 16 & 150 & 25 & 350 & 15 & 187.077 & 1045.5 & 186.896 & 1042.012 & 0.097 & 0.334 \\
\hline 17 & 150 & 25 & 350 & 25 & 205.205 & 1332.5 & 205.509 & 1327.019 & 0.148 & 0.411 \\
\hline 18 & 150 & 25 & 350 & 35 & 223.334 & 1619.5 & 224.292 & 1612.026 & 0.429 & 0.461 \\
\hline 19 & 150 & 35 & 150 & 15 & 68.484 & 1045.5 & 69.721 & 1046.497 & 1.807 & 0.095 \\
\hline 20 & 150 & 35 & 150 & 25 & 69.286 & 1168.5 & 71.153 & 1169.497 & 2.695 & 0.085 \\
\hline 21 & 150 & 35 & 150 & 35 & 70.088 & 1291.5 & 72.581 & 1288.510 & 3.557 & 0.231 \\
\hline 22 & 150 & 35 & 250 & 15 & 146.304 & 1168.5 & 146.552 & 1169.497 & 0.169 & 0.085 \\
\hline 23 & 150 & 35 & 250 & 25 & 151.787 & 1373.5 & 152.619 & 1374.497 & 0.548 & 0.073 \\
\hline 24 & 150 & 35 & 250 & 35 & 157.269 & 1578.5 & 158.946 & 1575.510 & 1.067 & 0.189 \\
\hline 25 & 150 & 35 & 350 & 15 & 232.833 & 1291.5 & 232.767 & 1288.510 & 0.028 & 0.231 \\
\hline 26 & 150 & 35 & 350 & 25 & 247.573 & 1578.5 & 248.207 & 1575.510 & 0.256 & 0.189 \\
\hline 27 & 150 & 35 & 350 & 35 & 262.312 & 1865.5 & 263.705 & 1860.517 & 0.531 & 0.267 \\
\hline 28 & 250 & 15 & 150 & 15 & 68.568 & 799.5 & 68.358 & 799.002 & 0.307 & 0.062 \\
\hline 29 & 250 & 15 & 150 & 25 & 71.276 & 922.5 & 71.740 & 921.005 & 0.651 & 0.162 \\
\hline 30 & 250 & 15 & 150 & 35 & 73.983 & 1045.5 & 75.076 & 1042.012 & 1.478 & 0.334 \\
\hline 31 & 250 & 15 & 250 & 15 & 131.973 & 922.5 & 131.304 & 921.005 & 0.507 & 0.162 \\
\hline 32 & 250 & 15 & 250 & 25 & 141.982 & 1127.5 & 142.133 & 1125.009 & 0.106 & 0.221 \\
\hline 33 & 250 & 15 & 250 & 35 & 151.991 & 1332.5 & 152.752 & 1327.019 & 0.501 & 0.411 \\
\hline 34 & 250 & 15 & 350 & 15 & 202.655 & 1045.5 & 202.408 & 1042.012 & 0.122 & 0.334 \\
\hline 35 & 250 & 15 & 350 & 25 & 224.657 & 1332.5 & 225.109 & 1327.019 & 0.201 & 0.411 \\
\hline
\end{tabular}


Table 8. Continued

\begin{tabular}{|c|c|c|c|c|c|c|c|c|c|c|}
\hline \multirow[b]{2}{*}{$\begin{array}{l}\text { Solution } \\
\text { No }\end{array}$} & \multirow[b]{2}{*}{$b$} & \multirow[b]{2}{*}{$t_{b}$} & \multirow[b]{2}{*}{$h$} & \multirow[b]{2}{*}{ th } & \multicolumn{2}{|c|}{ Mathemetical Solution } & \multicolumn{2}{|c|}{ FIL Solution } & \multicolumn{2}{|c|}{ Absolute Percent Error } \\
\hline & & & & & $M$ & $V$ & $M$ & $V$ & $E_{M}$ & $E_{V}$ \\
\hline 36 & 250 & 15 & 350 & 35 & 246.658 & 1619.5 & 247.412 & 1612.026 & 0.305 & 0.461 \\
\hline 37 & 250 & 25 & 150 & 15 & 95.371 & 1209.5 & 95.868 & 1214.981 & 0.522 & 0.453 \\
\hline 38 & 250 & 25 & 150 & 25 & 96.938 & 1332.5 & 98.170 & 1330.507 & 1.272 & 0.150 \\
\hline 39 & 250 & 25 & 150 & 35 & 98.504 & 1455.5 & 100.439 & 1451.016 & 1.964 & 0.308 \\
\hline 40 & 250 & 25 & 250 & 15 & 190.468 & 1332.5 & 189.854 & 1330.507 & 0.322 & 0.150 \\
\hline 41 & 250 & 25 & 250 & 25 & 197.988 & 1537.5 & 198.216 & 1528.033 & 0.115 & 0.616 \\
\hline 42 & 250 & 25 & 250 & 35 & 205.508 & 1742.5 & 206.658 & 1734.528 & 0.560 & 0.458 \\
\hline 43 & 250 & 25 & 350 & 15 & 293.666 & 1455.5 & 292.954 & 1451.016 & 0.243 & 0.308 \\
\hline 44 & 250 & 25 & 350 & 25 & 311.795 & 1742.5 & 311.425 & 1734.528 & 0.119 & 0.458 \\
\hline 45 & 250 & 25 & 350 & 35 & 329.923 & 2029.5 & 330.131 & 2019.036 & 0.063 & 0.516 \\
\hline 46 & 250 & 35 & 150 & 15 & 113.337 & 1619.5 & 114.940 & 1627.970 & 1.414 & 0.523 \\
\hline 47 & 250 & 35 & 150 & 25 & 114.140 & 1742.5 & 116.466 & 1746.486 & 2.038 & 0.229 \\
\hline 48 & 250 & 35 & 150 & 35 & 114.942 & 1865.5 & 118.016 & 1862.012 & 2.675 & 0.187 \\
\hline 49 & 250 & 35 & 250 & 15 & 238.359 & 1742.5 & 238.155 & 1746.486 & 0.085 & 0.229 \\
\hline 50 & 250 & 35 & 250 & 25 & 243.841 & 1947.5 & 244.238 & 1947.002 & 0.163 & 0.026 \\
\hline 51 & 250 & 35 & 250 & 35 & 249.323 & 2152.5 & 250.850 & 2146.023 & 0.613 & 0.301 \\
\hline 52 & 250 & 35 & 350 & 15 & 373.316 & 1865.5 & 372.279 & 1862.012 & 0.278 & 0.187 \\
\hline 53 & 250 & 35 & 350 & 25 & 388.056 & 2152.5 & 387.618 & 2146.023 & 0.113 & 0.301 \\
\hline 54 & 250 & 35 & 350 & 35 & 402.795 & 2439.5 & 404.248 & 2438.005 & 0.361 & 0.061 \\
\hline 55 & 350 & 15 & 150 & 15 & 94.371 & 1045.5 & 93.691 & 1046.497 & 0.721 & 0.095 \\
\hline 56 & 350 & 15 & 150 & 25 & 97.079 & 1168.5 & 96.847 & 1169.497 & 0.238 & 0.085 \\
\hline 57 & 350 & 15 & 150 & 35 & 99.786 & 1291.5 & 100.282 & 1288.510 & 0.497 & 0.231 \\
\hline 58 & 350 & 15 & 250 & 15 & 178.757 & 1168.5 & 177.686 & 1169.497 & 0.599 & 0.085 \\
\hline 59 & 350 & 15 & 250 & 25 & 188.766 & 1373.5 & 188.331 & 1374.497 & 0.231 & 0.073 \\
\hline 60 & 350 & 15 & 250 & 35 & 198.775 & 1578.5 & 198.716 & 1575.510 & 0.030 & 0.189 \\
\hline 61 & 350 & 15 & 350 & 15 & 270.517 & 1291.5 & 270.200 & 1288.510 & 0.117 & 0.231 \\
\hline 62 & 350 & 15 & 350 & 25 & 292.518 & 1578.5 & 292.938 & 1575.510 & 0.144 & 0.189 \\
\hline 63 & 350 & 15 & 350 & 35 & 314.519 & 1865.5 & 314.803 & 1860.517 & 0.090 & 0.267 \\
\hline 64 & 350 & 25 & 150 & 15 & 132.579 & 1619.5 & 132.910 & 1627.970 & 0.250 & 0.523 \\
\hline 65 & 350 & 25 & 150 & 25 & 134.146 & 1742.5 & 134.900 & 1746.486 & 0.562 & 0.229 \\
\hline 66 & 350 & 25 & 150 & 35 & 135.713 & 1865.5 & 137.291 & 1862.012 & 1.163 & 0.187 \\
\hline 67 & 350 & 25 & 250 & 15 & 262.143 & 1742.5 & 260.999 & 1746.486 & 0.436 & 0.229 \\
\hline 68 & 350 & 25 & 250 & 25 & 269.663 & 1947.5 & 269.175 & 1947.002 & 0.181 & 0.026 \\
\hline 69 & 350 & 25 & 250 & 35 & 277.183 & 2152.5 & 277.505 & 2146.023 & 0.116 & 0.301 \\
\hline 70 & 350 & 25 & 350 & 15 & 400.255 & 1865.5 & 398.938 & 1862.012 & 0.329 & 0.187 \\
\hline 71 & 350 & 25 & 350 & 25 & 418.384 & 2152.5 & 417.862 & 2146.023 & 0.125 & 0.301 \\
\hline 72 & 350 & 25 & 350 & 35 & 436.513 & 2439.5 & 437.617 & 2438.005 & 0.253 & 0.061 \\
\hline 73 & 350 & 35 & 150 & 15 & 158.191 & 2193.5 & 160.291 & 2209.444 & 1.328 & 0.727 \\
\hline 74 & 350 & 35 & 150 & 25 & 158.993 & 2316.5 & 161.511 & 2324.970 & 1.584 & 0.366 \\
\hline 75 & 350 & 35 & 150 & 35 & 159.795 & 2439.5 & 163.201 & 2436.012 & 2.131 & 0.143 \\
\hline 76 & 350 & 35 & 250 & 15 & 330.413 & 2316.5 & 330.029 & 2324.970 & 0.116 & 0.366 \\
\hline 77 & 350 & 35 & 250 & 25 & 335.895 & 2521.5 & 335.775 & 2526.483 & 0.036 & 0.198 \\
\hline 78 & 350 & 35 & 250 & 35 & 341.377 & 2726.5 & 342.483 & 2725.005 & 0.324 & 0.055 \\
\hline 79 & 350 & 35 & 350 & 15 & 513.799 & 2439.5 & 512.103 & 2436.012 & 0.330 & 0.143 \\
\hline 80 & 350 & 35 & 350 & 25 & 528.539 & 2726.5 & 527.189 & 2725.005 & 0.255 & 0.055 \\
\hline \multirow[t]{3}{*}{81} & 350 & 35 & 350 & 35 & 543.278 & 3013.5 & 545.060 & 3018.483 & 0.328 & 0.165 \\
\hline & & & & & & \multirow{2}{*}{\multicolumn{3}{|c|}{$\begin{array}{l}\text { Average Absolute Percent Error } \\
\text { Maximum Absolute Percent Error }\end{array}$}} & 0.724 & 0.256 \\
\hline & & & & & & & & & 3.557 & 0.810 \\
\hline
\end{tabular}

The validation of the fuzzy model has been proven with these values of $R, R^{2}$, errors given Table 8. The studies carried out up to this point are the applications of a typical fuzzy logic on this problem. The next process is the determination of the $b, t_{b}, h$, and $t_{h}$ dimensions of the I shaped crosssection for $\mathrm{M}_{\max }=100 \mathrm{kNm}$ and $\mathrm{V}_{\max }=1000 \mathrm{kN}$ using the FIL method. Since the de-fuzzification method of the WAM method is used in the FL model, the same method is also used in the FIL studies in this study.

\subsubsection{Application of FIL method on FL model constituted for problem 1}

When $\mathbf{M}_{\max }=100 \mathrm{kNm}$ bending moment value is entered as desired output into the program prepared for FIL method, $b, t_{b}, h$, and $t_{h}$ values were not obtained for $\% \quad 0$ error and membership sensitivities of $0.1,0.05,0.025,0.01,0.001$. It can be said that the reason for this depends on the level of sensitivity and problem structure and problem outputs. In other words, for the analysis with $0 \%$ error, it is required to study with much smaller 
sensitivities mathematically. Especially for outputs with multi-digit values after the comma, the sensitivity should be quite high in order to perform FIL studies with $0 \%$ error. In this problem, since the definitions of fuzzy output sets were made with multi-digit numbers after the comma, it is a very natural result that solutions cannot be found with the above mentioned sensitivity levels and for $0 \%$ error in the light of these explanations. This is an indication that the fuzzy model developed for this problem could not be constituted well. When the error amount is taken as $0.1 \%$ instead of $0 \%$, the sensitivity is taken as 0.1 and the FIL program is run, the FIL method produced results. In other words, even if the sensitivity is not high, solutions can be reached with a small increase in the amount of error. Thus, during the evaluation of this sample, the efficiency of FIL was tried to be investigated for the error $0.1 \%$ and for the membership sensitivity 0.1 in this problem.

Since there are 4 input parameters such as $h, t_{h}, b$ and $t_{b}$ in this problem, maximum 4 dimensional (4D) solutions can be made in this problem. For this reason, 1D, 2D, 3D and 4D computations were made by taking the error $0.1 \%$ and the membership sensitivity $0.1,11,165,1056$ and 2609 solutions and for the M output and 74, 442, 1794 and 4342 solutions for the $\mathrm{V}$ output were obtained respectively. The graphic regarding the number of results obtained from these solutions is given in Figure 15. Since the results obtained from these analyzes are too many, only 1D solution results and internal and external errors for $\mathrm{M}$ and $\mathrm{V}$ outputs are given as example solutions in Table 9 and Table 10, respectively.

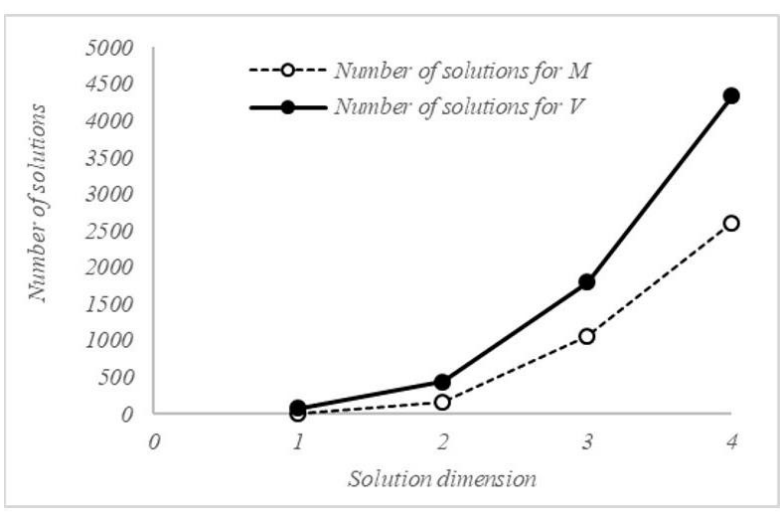

Figure 15. Number of solutions depending on solution dimension

As seen in Figure 15, as in the previous example, the number of solutions increased with the increase in analysis(solution) dimension. It can be clearly seen from this figure that the number of solutions obtained for output $\mathrm{V}$ is higher than the number of solutions obtained for output $\mathrm{M}$. The main factors in obtaining this result are the structure of the problem, the desired value of the output parameter and the number of fuzzy sets in the FL model for this parameter.

Table 9. 1D solution for $\mathrm{M}_{\max }=100 \mathrm{kNm}$ in problem 2

\begin{tabular}{|c|c|c|c|c|c|c|c|c|c|}
\hline $\begin{array}{c}\text { Solution } \\
\quad \text { No }\end{array}$ & $b$ & $t_{b}$ & $h$ & $t_{h}$ & $\begin{array}{c}\text { Mechanical } \\
\text { Solution }\end{array}$ & $\begin{array}{c}\text { FIL } \\
\text { Solution } \\
\text { (FILS) }\end{array}$ & $\begin{array}{c}\text { Desired } \\
\text { Value } \\
(D V)\end{array}$ & $\begin{array}{c}\text { Internal APE } \\
\frac{|F I L S-D V|}{D V} \times 100\end{array}$ & $\begin{array}{c}\text { External APE } \\
\frac{|M S-D V|}{D V} \times 100\end{array}$ \\
\hline 1 & 55 & 30 & 300 & 40 & 100.082 & 100.082 & 100 & 0.082 & 0.000 \\
\hline 2 & 65 & 40 & 300 & 20 & 99.941 & 99.941 & 100 & 0.059 & 0.000 \\
\hline 3 & 110 & 5 & 400 & 20 & 99.951 & 99.951 & 100 & 0.049 & 0.000 \\
\hline 4 & 50 & 16 & 400 & 20 & 100.164 & 99.977 & 100 & 0.023 & 0.187 \\
\hline 5 & 50 & 5 & 320 & 40 & 98.442 & 99.946 & 100 & 0.054 & 1.528 \\
\hline 6 & 100 & 40 & 240 & 10 & 99.264 & 100.008 & 100 & 0.008 & 0.750 \\
\hline 7 & 200 & 40 & 150 & 30 & 96.615 & 100.082 & 100 & 0.082 & 3.588 \\
\hline 8 & 400 & 5 & 260 & 20 & 98.781 & 99.911 & 100 & 0.089 & 1.144 \\
\hline 9 & 100 & 20 & 300 & 19 & 99.980 & 99.980 & 100 & 0.020 & 0.000 \\
\hline 10 & 200 & 20 & 200 & 17 & 99.926 & 99.926 & 100 & 0.074 & 0.000 \\
\hline 11 & 400 & 5 & 300 & 9.5 & 99.961 & 99.961 & 100 & 0.039 & 0.000 \\
\hline \multicolumn{8}{|c|}{ Average APE } & 0.053 & 0.654 \\
\hline \multicolumn{8}{|c|}{ Max APE } & 0.089 & 3.588 \\
\hline
\end{tabular}


Table 10. 1D solution for $\mathrm{V}_{\max }=1000 \mathrm{kN}$ in problem 2

\begin{tabular}{|c|c|c|c|c|c|c|c|c|c|}
\hline $\begin{array}{c}\text { Solution } \\
\quad \text { No }\end{array}$ & $b$ & $t_{b}$ & $h$ & $t_{h}$ & $\begin{array}{c}\text { Mechanical } \\
\text { Solution }\end{array}$ & $\begin{array}{c}\text { FIL } \\
\text { Solution } \\
(\text { FILS })\end{array}$ & $\begin{array}{c}\text { Desired } \\
\text { Value } \\
(D V)\end{array}$ & $\begin{array}{c}\text { Internal APE } \\
\frac{|F I L S-D V|}{D V} \times 100\end{array}$ & $\begin{array}{c}\text { External APE } \\
\frac{|M S-D V|}{D V} \times 100\end{array}$ \\
\hline 1 & 80 & 20 & 300 & 30 & 1000.4 & 1000.4 & 1000 & 0.04 & 0 \\
\hline 2 & 70 & 30 & 200 & 40 & 1000.4 & 1000.4 & 1000 & 0.04 & 0 \\
\hline 3 & 70 & 30 & 400 & 20 & 1000.4 & 1000.4 & 1000 & 0.04 & 0 \\
\hline 4 & 160 & 10 & 300 & 30 & 1000.4 & 1000.4 & 1000 & 0.04 & 0 \\
\hline 5 & 170 & 30 & 50 & 40 & 1000.4 & 1000.4 & 1000 & 0.04 & 0 \\
\hline 6 & 170 & 30 & 100 & 20 & 1000.4 & 1000.4 & 1000 & 0.04 & 0 \\
\hline 7 & 170 & 30 & 200 & 10 & 1000.4 & 1000.4 & 1000 & 0.04 & 0 \\
\hline 8 & 170 & 30 & 400 & 5 & 1000.4 & 1000.4 & 1000 & 0.04 & 0 \\
\hline 9 & 140 & 40 & 50 & 20 & 1000.4 & 1000.4 & 1000 & 0.04 & 0 \\
\hline 10 & 140 & 40 & 100 & 10 & 1000.4 & 1000.4 & 1000 & 0.04 & 0 \\
\hline 11 & 140 & 40 & 200 & 5 & 1000.4 & 1000.4 & 1000 & 0.04 & 0 \\
\hline 12 & 210 & 10 & 200 & 40 & 1000.4 & 1000.4 & 1000 & 0.04 & 0 \\
\hline 13 & 210 & 10 & 400 & 20 & 1000.4 & 1000.4 & 1000 & 0.04 & 0 \\
\hline 14 & 280 & 20 & 50 & 20 & 1000.4 & 1000.4 & 1000 & 0.04 & 0 \\
\hline 15 & 280 & 20 & 100 & 10 & 1000.4 & 1000.4 & 1000 & 0.04 & 0 \\
\hline 16 & 230 & 20 & 100 & 30 & 1000.4 & 1000.4 & 1000 & 0.04 & 0 \\
\hline 17 & 280 & 20 & 200 & 5 & 1000.4 & 1000.4 & 1000 & 0.04 & 0 \\
\hline 18 & 230 & 20 & 300 & 10 & 1000.4 & 1000.4 & 1000 & 0.04 & 0 \\
\hline 19 & 320 & 5 & 300 & 30 & 1000.4 & 1000.4 & 1000 & 0.04 & 0 \\
\hline 20 & 310 & 10 & 200 & 30 & 1000.4 & 1000.4 & 1000 & 0.04 & 0 \\
\hline 21 & 310 & 10 & 300 & 20 & 1000.4 & 1000.4 & 1000 & 0.04 & 0 \\
\hline 22 & 50 & 32 & 300 & 30 & 1000.4 & 1000.4 & 1000 & 0.04 & 0 \\
\hline 23 & 100 & 16 & 300 & 30 & 1000.4 & 1000.4 & 1000 & 0.04 & 0 \\
\hline 24 & 100 & 21 & 200 & 40 & 1000.4 & 1000.4 & 1000 & 0.04 & 0 \\
\hline 25 & 100 & 21 & 400 & 20 & 1000.4 & 1000.4 & 1000 & 0.04 & 0 \\
\hline 26 & 100 & 31 & 200 & 30 & 1000.4 & 1000.4 & 1000 & 0.04 & 0 \\
\hline 27 & 100 & 31 & 300 & 20 & 1000.4 & 1000.4 & 1000 & 0.04 & 0 \\
\hline 28 & 200 & 8 & 300 & 30 & 1000.4 & 1000.4 & 1000 & 0.04 & 0 \\
\hline 29 & 200 & 28 & 50 & 20 & 1000.4 & 1000.4 & 1000 & 0.04 & 0 \\
\hline 30 & 200 & 28 & 100 & 10 & 1000.4 & 1000.4 & 1000 & 0.04 & 0 \\
\hline 31 & 200 & 23 & 100 & 30 & 1000.4 & 1000.4 & 1000 & 0.04 & 0 \\
\hline 32 & 200 & 28 & 200 & 5 & 1000.4 & 1000.4 & 1000 & 0.04 & 0 \\
\hline 33 & 200 & 23 & 300 & 10 & 1000.4 & 1000.4 & 1000 & 0.04 & 0 \\
\hline 34 & 300 & 7 & 200 & 40 & 1000.4 & 1000.4 & 1000 & 0.04 & 0 \\
\hline 35 & 300 & 7 & 400 & 20 & 1000.4 & 1000.4 & 1000 & 0.04 & 0 \\
\hline 36 & 300 & 17 & 50 & 40 & 1000.4 & 1000.4 & 1000 & 0.04 & 0 \\
\hline 37 & 300 & 17 & 100 & 20 & 1000.4 & 1000.4 & 1000 & 0.04 & 0 \\
\hline 38 & 300 & 17 & 200 & 10 & 1000.4 & 1000.4 & 1000 & 0.04 & 0 \\
\hline 39 & 300 & 17 & 400 & 5 & 1000.4 & 1000.4 & 1000 & 0.04 & 0 \\
\hline 40 & 400 & 14 & 50 & 20 & 1000.4 & 1000.4 & 1000 & 0.04 & 0 \\
\hline 41 & 400 & 14 & 100 & 10 & 1000.4 & 1000.4 & 1000 & 0.04 & 0 \\
\hline 42 & 400 & 14 & 200 & 5 & 1000.4 & 1000.4 & 1000 & 0.04 & 0 \\
\hline 43 & 50 & 5 & 390 & 30 & 1000.4 & 1000.4 & 1000 & 0.04 & 0 \\
\hline 44 & 50 & 10 & 280 & 40 & 1000.4 & 1000.4 & 1000 & 0.04 & 0 \\
\hline 45 & 50 & 20 & 340 & 30 & 1000.4 & 1000.4 & 1000 & 0.04 & 0 \\
\hline 46 & 50 & 30 & 230 & 40 & 1000.4 & 1000.4 & 1000 & 0.04 & 0 \\
\hline 47 & 100 & 5 & 280 & 40 & 1000.4 & 1000.4 & 1000 & 0.04 & 0 \\
\hline 48 & 100 & 10 & 340 & 30 & 1000.4 & 1000.4 & 1000 & 0.04 & 0 \\
\hline 49 & 100 & 30 & 310 & 20 & 1000.4 & 1000.4 & 1000 & 0.04 & 0 \\
\hline 50 & 100 & 40 & 140 & 30 & 1000.4 & 1000.4 & 1000 & 0.04 & 0 \\
\hline 51 & 100 & 40 & 210 & 20 & 1000.4 & 1000.4 & 1000 & 0.04 & 0 \\
\hline 52 & 200 & 5 & 340 & 30 & 1000.4 & 1000.4 & 1000 & 0.04 & 0 \\
\hline 53 & 200 & 20 & 140 & 30 & 1000.4 & 1000.4 & 1000 & 0.04 & 0 \\
\hline 54 & 200 & 20 & 210 & 20 & 1000.4 & 1000.4 & 1000 & 0.04 & 0 \\
\hline 55 & 300 & 5 & 230 & 40 & 1000.4 & 1000.4 & 1000 & 0.04 & 0 \\
\hline 56 & 300 & 10 & 310 & 20 & 1000.4 & 1000.4 & 1000 & 0.04 & 0 \\
\hline 57 & 400 & 10 & 140 & 30 & 1000.4 & 1000.4 & 1000 & 0.04 & 0 \\
\hline 58 & 400 & 10 & 210 & 20 & 1000.4 & 1000.4 & 1000 & 0.04 & 0 \\
\hline 59 & 50 & 5 & 300 & 39 & 1000.4 & 1000.4 & 1000 & 0.04 & 0 \\
\hline 60 & 50 & 10 & 400 & 28 & 1000.4 & 1000.4 & 1000 & 0.04 & 0 \\
\hline 61 & 50 & 20 & 300 & 34 & 1000.4 & 1000.4 & 1000 & 0.04 & 0 \\
\hline 62 & 50 & 30 & 400 & 23 & 1000.4 & 1000.4 & 1000 & 0.04 & 0 \\
\hline
\end{tabular}


Table 10. Continued

\begin{tabular}{|c|c|c|c|c|c|c|c|c|c|}
\hline $\begin{array}{l}\text { Solution } \\
\quad \text { No }\end{array}$ & $b$ & $t_{b}$ & $h$ & $t_{h}$ & $\begin{array}{c}\text { Mechanical } \\
\text { Solution }\end{array}$ & $\begin{array}{c}\text { FIL } \\
\text { Solution } \\
(\text { FILS) }\end{array}$ & $\begin{array}{l}\text { Desired } \\
\text { Value } \\
(D V)\end{array}$ & $\begin{array}{c}\text { Internal APE } \\
\frac{|F I L S-D V|}{D V} \times 100\end{array}$ & $\begin{array}{c}\text { External APE } \\
\frac{|M S-D V|}{D V} \times 100\end{array}$ \\
\hline 63 & 100 & 5 & 400 & 28 & 1000.4 & 1000.4 & 1000 & 0.04 & 0 \\
\hline 64 & 100 & 10 & 300 & 34 & 1000.4 & 1000.4 & 1000 & 0.04 & 0 \\
\hline 65 & 100 & 30 & 200 & 31 & 1000.4 & 1000.4 & 1000 & 0.04 & 0 \\
\hline 66 & 100 & 40 & 200 & 21 & 1000.4 & 1000.4 & 1000 & 0.04 & 0 \\
\hline 67 & 100 & 40 & 300 & 14 & 1000.4 & 1000.4 & 1000 & 0.04 & 0 \\
\hline 68 & 200 & 5 & 300 & 34 & 1000.4 & 1000.4 & 1000 & 0.04 & 0 \\
\hline 69 & 200 & 20 & 200 & 21 & 1000.4 & 1000.4 & 1000 & 0.04 & 0 \\
\hline 70 & 200 & 20 & 300 & 14 & 1000.4 & 1000.4 & 1000 & 0.04 & 0 \\
\hline 71 & 300 & 5 & 400 & 23 & 1000.4 & 1000.4 & 1000 & 0.04 & 0 \\
\hline 72 & 300 & 10 & 200 & 31 & 1000.4 & 1000.4 & 1000 & 0.04 & 0 \\
\hline 73 & 400 & 10 & 200 & 21 & 1000.4 & 1000.4 & 1000 & 0.04 & 0 \\
\hline 74 & 400 & 10 & 300 & 14 & 1000.4 & 1000.4 & 1000 & 0.04 & 0 \\
\hline \multicolumn{8}{|c|}{ Average APE } & 0.04 & 0 \\
\hline \multicolumn{8}{|c|}{$\begin{array}{r}\text { Average APE } \\
\text { Max APE }\end{array}$} & 0.04 & 0 \\
\hline
\end{tabular}

While the number of solutions increases depending on the analysis dimension, a serious increase can be seen in the solution time. As can be seen in Figure 16 for Problem-2, the increase in the number of dimensions caused a serious increase in the solution time. Other parameters that may affect the solution time, fuzzy set numbers of input and output parameters, number of rules, acceptable error amounts, sensitivity level in the FIL and etc. It is worth noting here that, Figure 16 shows the time spent in the solutions implemented simultaneously for $\mathrm{M}$ and $\mathrm{V}$ in the program developed within the scope of this study.

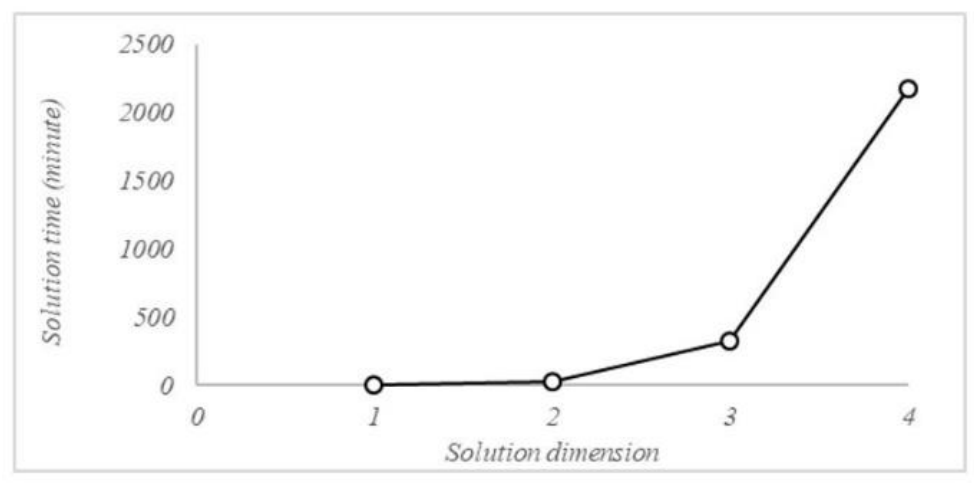

Figure 16. Solution time depending upon analysis dimension

Internal and external errors depending on the solution size are given in Figure 17 and Figure 18 for output M, and in Figure 19 and Figure 20 for the output of V, respectively. As seen in Figure 17 and Figure 19, the maximum internal error for both outputs is below $0.1 \%$ and the average internal error is around $0.05 \%$. This is an indication that FIL can provide solutions within the desired sensitivity and error limits.

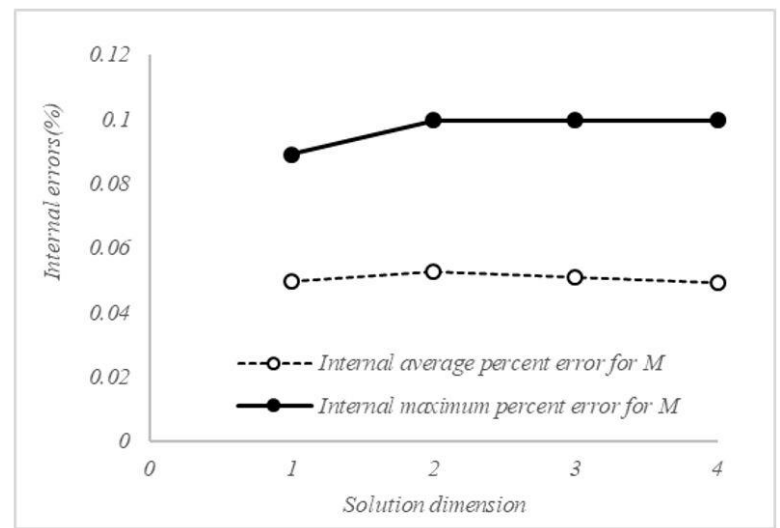

Figure 17. Internal percent errors for $M$ output 


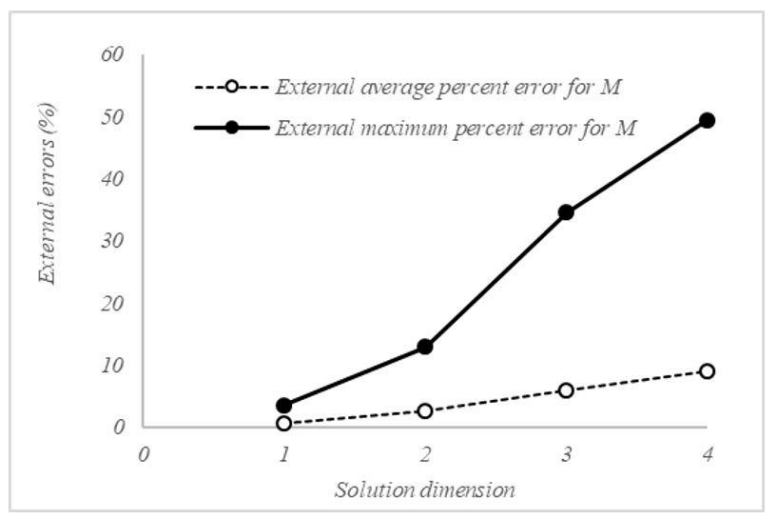

Figure 18. External percent errors for $M$ output

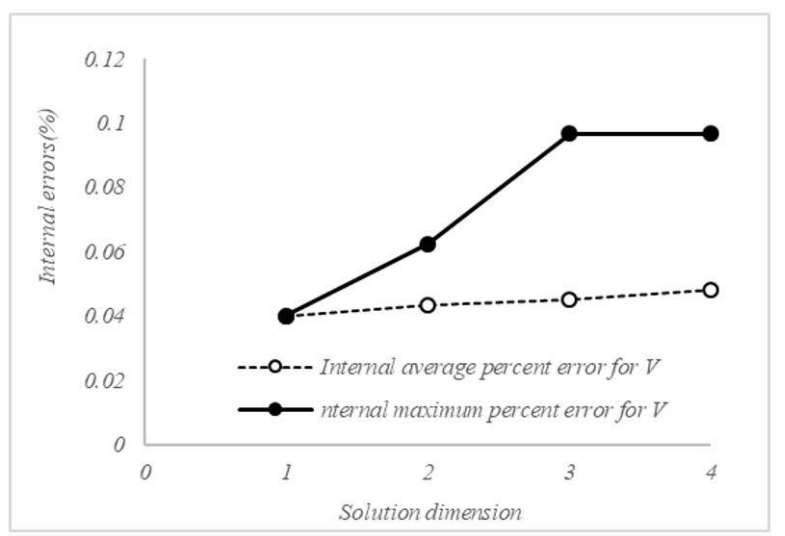

Figure 19. Internal percent errors for $\mathrm{V}$ output

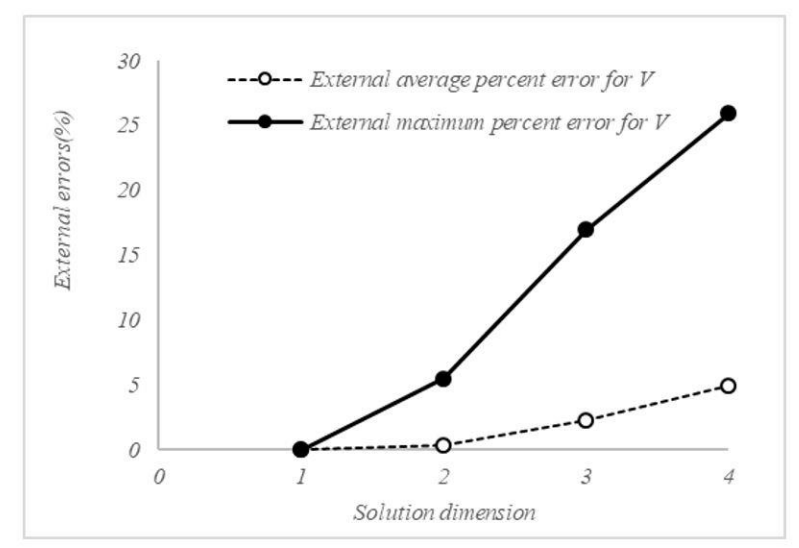

Figure 20. External percent errors for $\mathrm{V}$ output

When Figure 18 is examined, using the input parameter values obtained by FIL, the desired $M$ output were computed with an average external error of $0.72 \%, 2.584 \% 5.941$ and $8.999 \%$ in $1 \mathrm{D}$, 2D, 3D and 4D analyzes respectively. These results prove that FIL produces good results. On the other hand, on the same figure, it is seen that the desired $\mathrm{M}$ output is computed with a maximum of $3.588 \%$, $12.983 \%, 34.589 \%$ and $49.461 \%$ external error in 1D, 2D, 3D and 4D analyzes, respectively. Considering these maximum errors, it has been revealed that not all of the solutions produced by FIL are correct and although the average error values seem reasonable, as the number of analysis dimension increases some solutions may be not correct enough. Especially in multi-dimensional analyzes, mistakes made in FL model for each dimension before or not being sensitive enough during the constitution of FL model play an important role in obtaining the desired results that are not accurate. With the more sensitive constitution of the FL model, it is possible to reduce the max external errors and thus obtain very low values in the average error. The sensitivity of the FL model should be increased especially at solution points corresponding to local minimums and local maximums. In short, since the FIL method is based on FL, the sensitivity and errors in the results obtained in FIL are directly related to the FL model.

When Figure 20 is examined, it can be immediately noticed that the comments made for the $\mathrm{M}$ output are valid for the $\mathrm{V}$ output. In this figure, the maximum average and maximum errors for the $\mathrm{V}$ output were obtained as $4.936 \%$ and $25.954 \%$, respectively, in 4 dimensional analyses. In Figure 18 , these values for the M output are approximately twice $(8.999 \%$ and $49.461 \%)$ that of the V output. Here, if the average errors can be reduced below $1 \%$, it is foreseen that the maximum errors may remain within acceptable limits.

In this problem, the solution capability of FIL is also examined depending on the acceptable output error. For this purpose, the number of 1D dimensional solutions obtained in FIL depending on the acceptable amount of error is given in Figure 21 for both outputs. As can be seen from this figure, as the amount of acceptable output error increased, the number of solutions increased. As a result of the 1D analyses for the acceptable error amount of $0.1 \%, 1 \%, 2.5 \%, 5 \%, 7.5 \%$ and $10 \%, 11,94,234$, 451,633 and 810 solutions for the M output, 74, 120, 396, 722, 922 and 1190 solutions for the V output were obtained respectively. These results, which is an expected situation, are due to the fact that the solutions that could not be obtained at the previous error level with small differences can be obtained at the increasing acceptable error level, and the problem has other solutions within the acceptable error limits, as stated in Problem 1. The main factors in obtaining more solutions for the output $\mathrm{V}$ are the structure of the problem, the desired value of the output parameter and the number of fuzzy sets in the FL model for this parameter. 


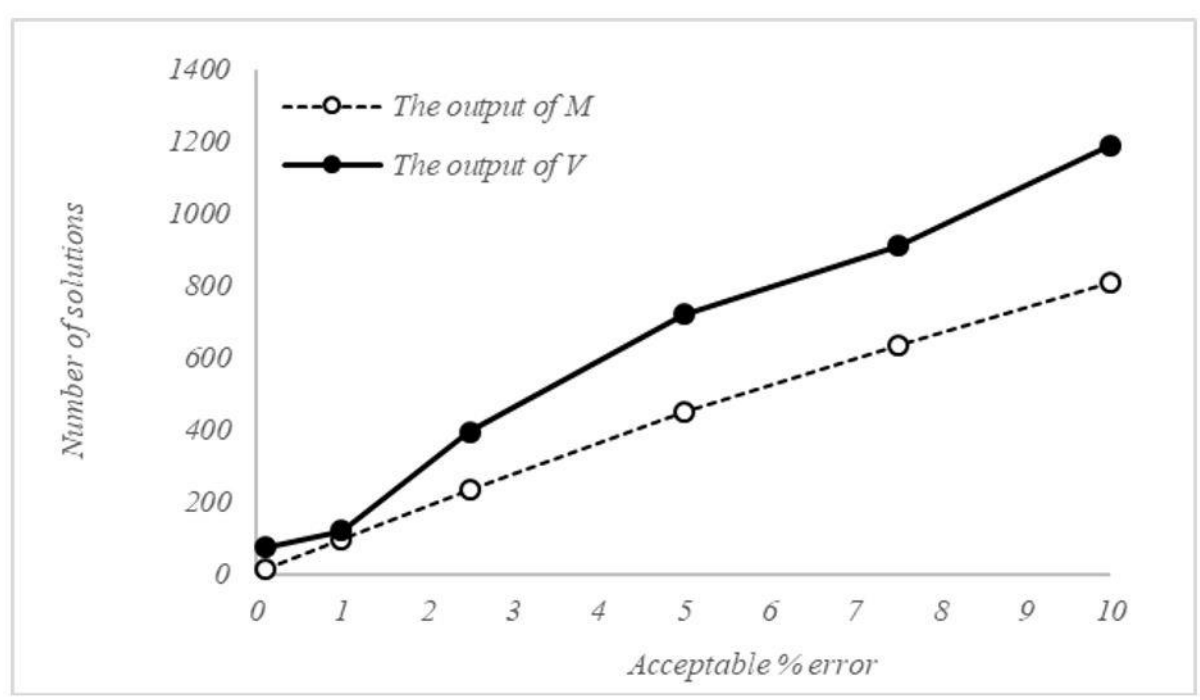

Figure 21. The number of solutions depended on acceptable error level

Depending on the acceptable error values for the $\mathrm{M}$ and $\mathrm{V}$ outputs, the average and maximum internal and external errors in the analysis obtained in the FIL are given in Figure 22, Figure 23, Figure 24 and Figure 25. As can be seen from Figure 22 and Figure 24, the maximum and average internal errors obtained for the $\mathrm{M}$ and $\mathrm{V}$ output parameters increased with the increase of the acceptable output error value. This is an expected natural result. The fact that the maximum internal errors are lower than the acceptable error levels shows the efficiency of the FIL method in 1D analysis. On the other hand, for $\mathrm{M}$, the external average error was about $0.5 \%$ and the external maximum error was about $4 \%$ (See Figure 23). Despite the increase in acceptable output error for $\mathrm{V}$, the maximum and average external errors were obtained as $0 \%$ (See Figure 25). In other words, with the values of the input parameters determined by the FIL method for $\mathrm{V}$, even at different acceptable error levels, results that are perfectly suitable for the mathematical solution were obtained. This demonstrates that the FIL method produces $100 \%$ accurate results at acceptable output error levels $(0.1 \%-10 \%$ in this problem) for the $\mathrm{V}$ output and how effective it can be for low dimensional analyses (1D in this problem) in sensitive FL models.

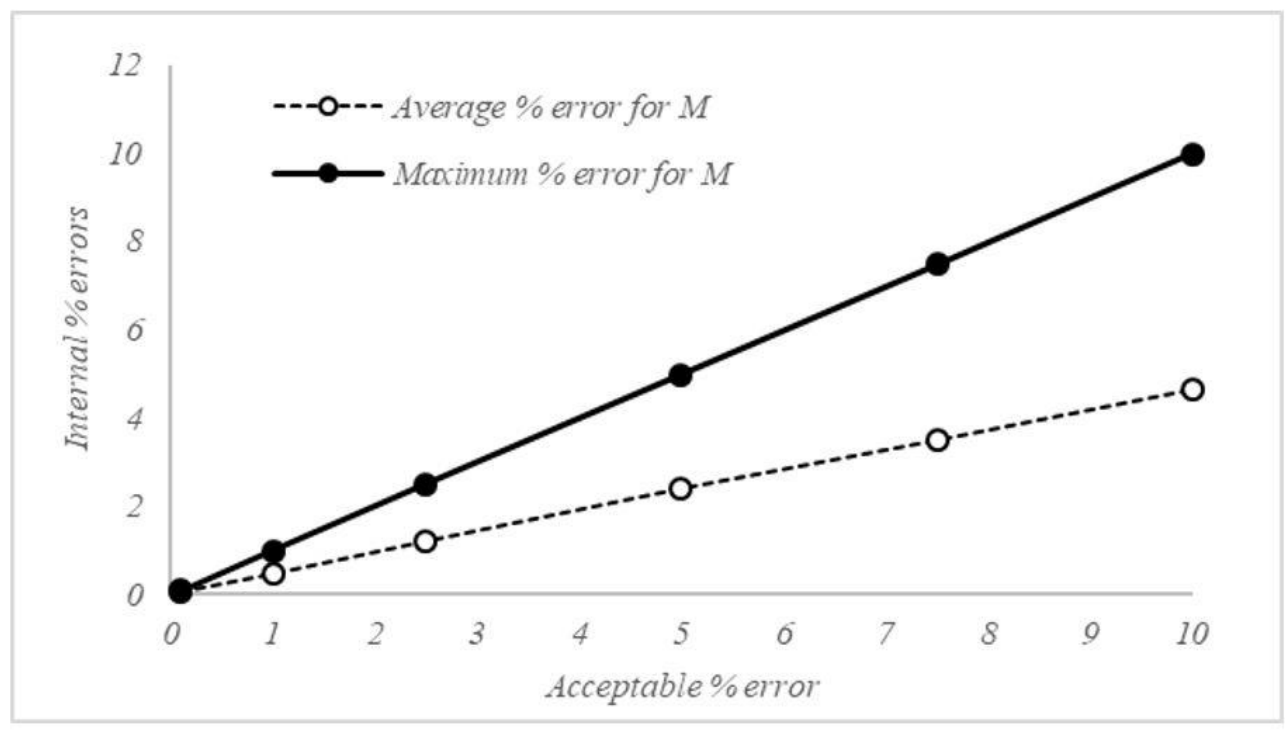

Figure 22. Average and maximum internal \% errors in FIL for M depending on acceptable output error value 


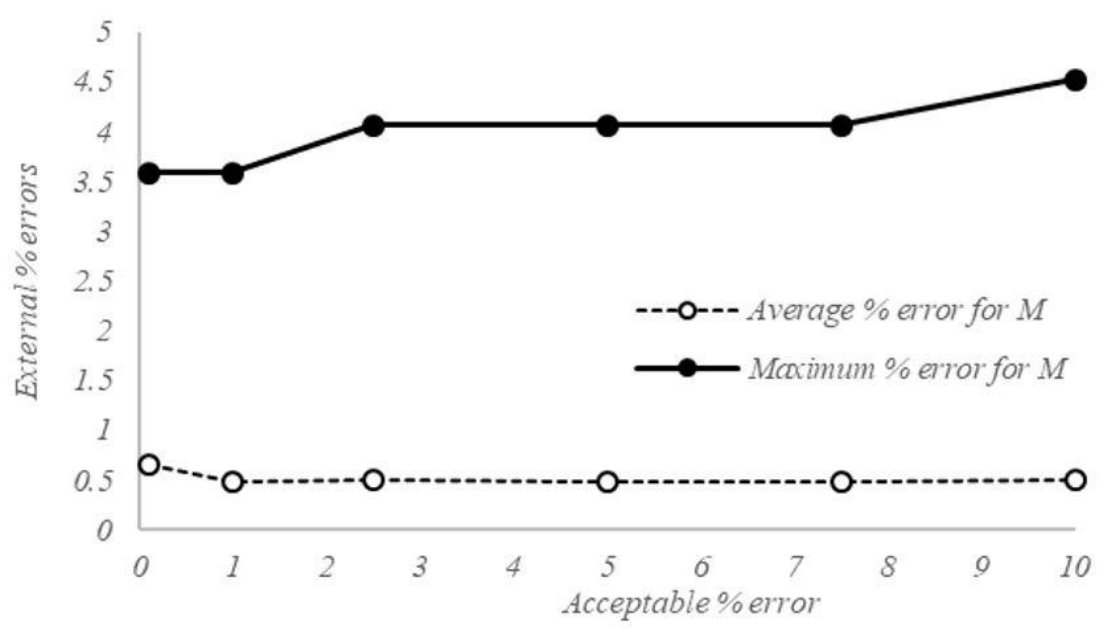

Figure 23. Average and maximum external \% errors in FIL for $\mathrm{M}$ depending on acceptable output error value

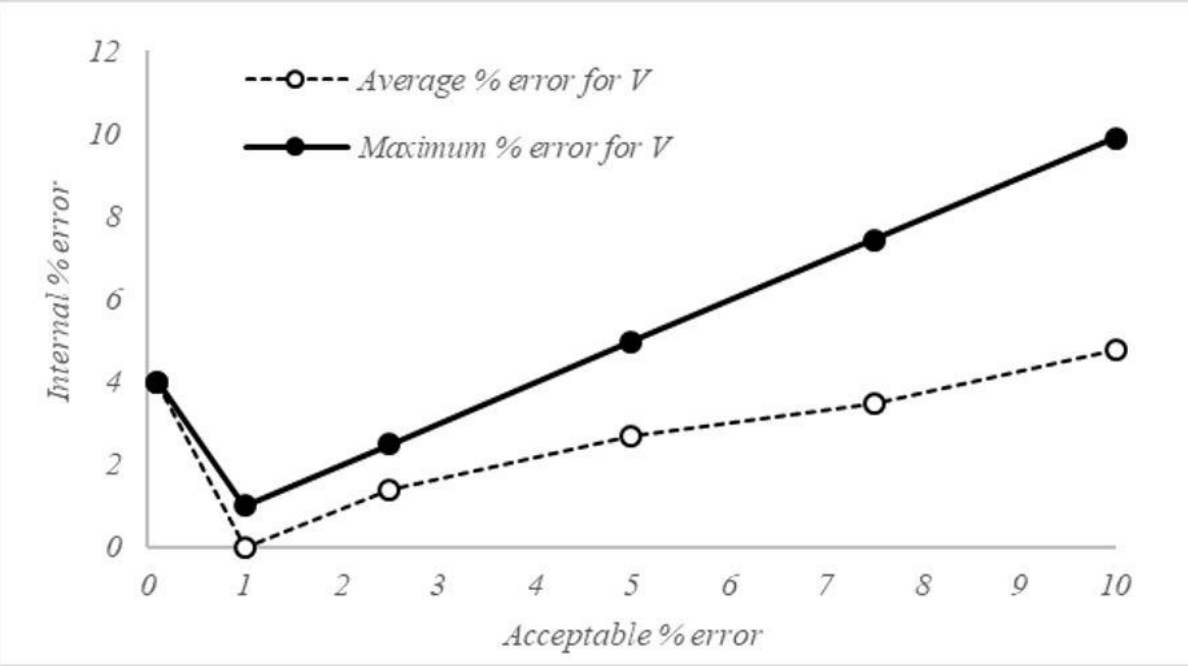

Figure 24. Average and maximum internal \% errors in FIL for V depending on acceptable output error value

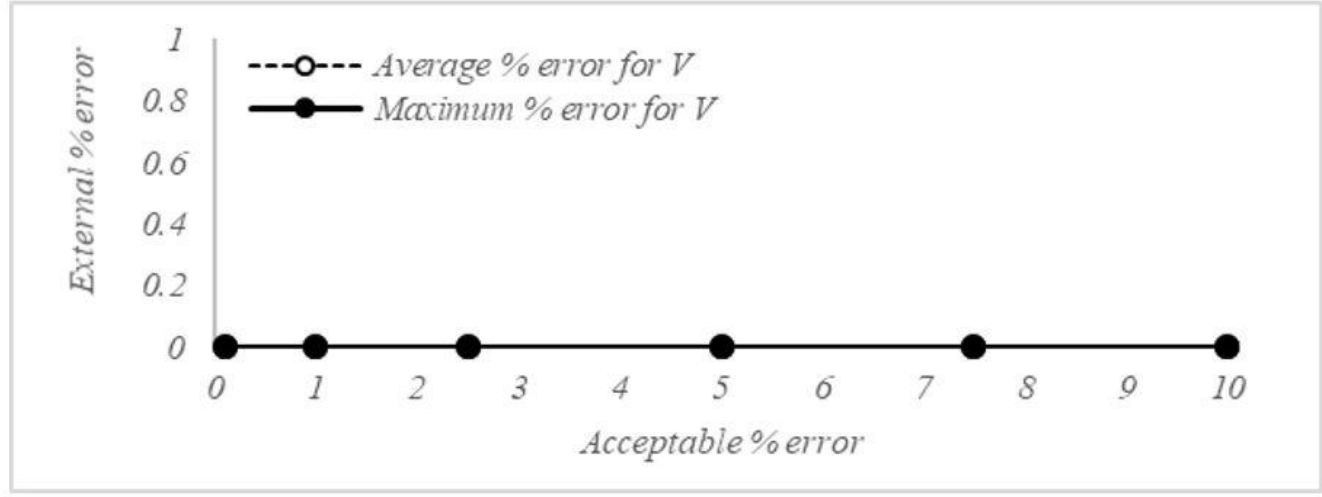

Figure 25. Average and maximum external \% errors in FIL for V depending on acceptable output error value

When the dimension and error analysis results are considered together, for example, solutions with big maximum external error values are obtained even at $0.1 \%$ acceptable output error level in $4 \mathrm{D}$ 
solutions. This reveals that it is necessary to be very careful in using the FIL method in big dimensional analyzes. This not shows that FIL is not effective in big dimensional analyzes. This means that, the FIL method can only be used with very sensitive FL models in big dimensional analyzes (in multiparameter problems). Errors that occur in FIL analysis are not caused by the FIL method. These errors are the errors of the FL model used with the FIL method.

Since the solutions based on sensitivity are examined in problem 1, there are no discussions based on sensitivity in problem 2 .

\section{Summary, conclusions and suggestions}

In this study published in two parts, similar to the FL method which was developed by using forwardoriented inferences (from variables toward results) made by the human being, the FIL method has been tried to be improved by the inspiration from the backward (from results toward variables).

During the development of the FIL method, it was understood that it could be used and improved with many different methods. However, since this study is mainly aimed at introducing the method, it has been tried to be explained as simple as possible without going into too much detail.

Considering all the evaluations and examinations made above on these two problems, the following points can be summarized for FIL.

1 - The FIL method is based on FL.

2 - There is no need to constitute special data for the FIL. It can be applied on a FL model directly.

3 - A large number of alternative solutions can be obtained as a result of an FIL analysis.

4 - FIL can produce very effective results in small dimensional analysis.

5 - Very sensitive FL models should be constituted for big dimensional (multi-parameter) analyzes of FIL, and FIL should be used carefully for big dimensional analysis.

The following results and suggestions can be written considering the overall study.

1 - Considering internal error evaluations, it is predicted that FRL can be used very effectively in control problems.

2 - Since the FIL method can be applied on fuzzy logic models constituted for problems with multiple outputs, it is thought that it can also be used in optimization studies.
Finally, the biggest result obtained from this study is that inferences similar to the backward inferences made by human beings can be achieved with the FIL method. The fact that more than one result can be reached in backward inferences in the method explains why human beings have difficulty in making backward inferences. However, in order to be able to perform backward inference successfully by FIL method, there is a need for a well-developed FL model that can calculate with very low errors. This reveals that more mistakes can be made in backward inferences in situations where human beings have not experienced very well and explains why people do not prefer to make backward inferences much. The fact that the same data can be used in forward and backward inference in FL and FIL methods, just as human beings use, shows that the combined use of these two methods will support and reinforce each other in the field of artificial intelligence. In addition to all these, it can be easily said that the FIL method can be supported and developed with many methods and algorithms in the future and can be used successfully in many areas together with the FL method.

\section{References}

Altaş, İ. H. (1999a). Bulanık Mantık: Bulanıklılık Kavramı. Enerji, Elektrik, Elektromekanik$3 e, 62,80-85$.

Altaş, İ. H. (1999b). Bulanık mantık: Bulanık denetim. Enerji, Elektrik, Elektromekanik-3e, 64(1999), 76-81.

Altaş, I. H. (2017). Fuzzy Logic Control in Energy Systems with Design Applications in $M A T L A B \circledR /$ Simulink ${ }^{\circledR}(91)$. IET.

Chopard, B. and Droz, M. (1998). Cellular automata (Vol. 1). Berlin, Germany: Springer.

Cvijović, D. and Klinowski, J. (1995). Taboo search: an approach to the multiple minima problem. Science, $267 \quad$ (5198), 664-666. https://doi.org/10.1126/science.267.5198.664

Erdun, H. (2020). Fuzzy Logic Defuzzification (Bulanıklaştırma) Methods with Examples: Erișim adresi https://www.researchgate.net/publication/34419 6954_Fuzzy_Logic_Defuzzification_Bulaniklas tirma_Methods_with_Examples

Harris, J. (2005). Fuzzy logic applications in engineering science (Vol. 29). Springer Science $\&$ Business Media. 
Jain, A. K., Mao, J. and Mohiuddin, K. M. (1996). Artificial neural networks: A tutorial. Computer, 29(3), 31-44. https://doi.org/10.1109/2.485891

Kennedy, J. and Eberhart, R. (1995). Particle swarm optimization. In Proceedings of ICNN'95international conference on neural networks, 4, 1942-1948.

Karaboga, D. and Akay, B. (2009). A comparative study of artificial bee colony algorithm. Applied mathematics and computation, 214(1), 108-132. https://doi.org/10.1016/j.amc.2009.03.090

Mamdani, E. H. and Assilian, S. (1975). An experiment in linguistic synthesis with a fuzzy logic controller. International Journal of ManMachine Studies, 7(1), 1-13. https://doi.org/10.1016/S0020-7373(75)80002-2

Mamdani, E. H. (1976). Advances in the linguistic synthesis of fuzzy controllers. International Journal of Man-Machine Studies, 8(6), 669-678. https://doi.org/10.1016/S0020-7373(76)80028-4

Moscato, P., Cotta, C. and Mendes, A. (2004). Memetic algorithms. In new optimization techniques in engineering (pp. 53-85). Springer, Berlin, Heidelberg.

Öztekin, E. ve Filiz, K. (2015). Beton gerilme şekildeğiştirme ĕgrilerinin bulanı mantık yaklaşımıyla elde edilmesi. Mühendislikte Yeni Teknolojiler Sempozyumu, Bayburt.

Parpinelli, R. S., Lopes, H. S. and Freitas, A. A. (2002). Data mining with an ant colony optimization algorithm. IEEE Transactions On Evolutionary Computation, 6(4), 321-332. https://doi.org/10.1109/TEVC.2002.802452

Pörge, B. (2019). Investigation of reliabilities of the triaxial concrete compressive strength models by fuzzy logic approach, Yüksek Lisans Tezi, Bayburt Üniversitesi Fen Bilimleri Enstitüsü, Bayburt.

Rajabioun, R. (2011). Cuckoo optimization algorithm. Applied Soft Computing, 11(8), 5508-5518.
Ross, T. J. (2004). Fuzzy logic with engineering applications (Vol. 2). New York: Wiley.

Terano, T., Asai, K. and Sugeno, M. (1992). Fuzzy systems theory and its applications. Academic Press Professional, Inc.

Tanaka, K. (1997). An introduction to fuzzy logic for practical applications.

Van Laarhoven, P. J. and Aarts, E. H. (1987). Simulated annealing. In simulated annealing: Theory and applications (pp. 7-15). Springer.

Whitley, D. (1994). A genetic algorithm tutorial. Statistics and Computing, 4(2), 65-85. https://doi.org/10.1007/BF00175354

Yager, R. R. and Zadeh, L. A. (Eds.). (2012). An introduction to fuzzy logic applications in intelligent systems (Vol. 165). Springer Science $\&$ Business Media.

Yang, X. S. and Gandomi, A. H. (2012). Bat algorithm: a novel approach for global engineering optimization. Engineering Computations, 29(5), 464-483. https://doi.org/10.1108/02644401211235834

Zadeh, L. A. (1965). Information and control. Fuzzy Sets, 8(3), 338-353. https://doi.org/10.1016/S0019-9958(65)90241$\mathrm{X}$

Zadeh, L. A. (1973). Outline of a new approach to the analysis of complex systems and decision processes. IEEE Transactions on systems, Man and Cybernetics, (1), 28-44. https://doi.org/10.1109/TSMC.1973.5408575

Zadeh, L. A. (1975). The concept of a linguistic variable and its application to approximate reasoning-III. Information Siences, 9(1), 43-80. https://doi.org/10.1016/0020-0255(75)90036-5 